\title{
Understanding the Role of the Gut Microbiome and Microbial Metabolites in Non-Alcoholic Fatty Liver Disease: Current Evidence and Perspectives
}

\author{
Natalia Vallianou ${ }^{1, *}$, Gerasimos Socrates Christodoulatos ${ }^{2}$, Irene Karampela ${ }^{3} \mathbb{D}$, Dimitrios Tsilingiris ${ }^{4}$, \\ Faidon Magkos ${ }^{5}\left(\mathbb{D}\right.$, Theodora Stratigou ${ }^{6} \mathbb{D}$, Dimitris Kounatidis ${ }^{1}$ and Maria Dalamaga ${ }^{2} \mathbb{D}$
}

1 Department of Internal Medicine, Evaggelismos General Hospital, 45-47 Ypsilantou Street, 10676 Athens, Greece; dimitriskounatidis82@outlook.com

2 Department of Biological Chemistry, Medical School, National and Kapodistrian University of Athens, 75 Mikras Asias, Goudi, 11527 Athens, Greece; gerchristod82@hotmail.com (G.S.C.); madalamaga@med.uoa.gr (M.D.)

3 2nd Department of Critical Care, Medical School, University of Athens, Attikon General University Hospital, 1 Rimini Street, Chaidari, 12462 Athens, Greece; eikaras1@gmail.com

4 First Department of Propaedeutic Internal Medicine, School of Medicine, National and Kapodistrian University of Athens, Laiko General Hospital, 17 St Thomas Street, 11527 Athens, Greece; tsilingirisd@gmail.com

5 Department of Nutrition, Exercise, and Sports, University of Copenhagen, 2000 Frederiksberg, Denmark; fma@nexs.ku.dk

check for updates

Citation: Vallianou, N.; Christodoulatos, G.S.; Karampela, I.; Tsilingiris, D.; Magkos, F.; Stratigou, T.; Kounatidis, D.; Dalamaga, M. Understanding the Role of the Gut Microbiome and Microbial Metabolites in Non-Alcoholic Fatty Liver Disease: Current Evidence and Perspectives. Biomolecules 2022, 12, 56. https://doi.org/10.3390/

biom12010056

Academic Editor: Vladimir N. Uversky

Received: 14 November 2021 Accepted: 30 December 2021 Published: 31 December 2021

Publisher's Note: MDPI stays neutral with regard to jurisdictional claims in published maps and institutional affiliations.

Copyright: (C) 2021 by the authors. Licensee MDPI, Basel, Switzerland. This article is an open access article distributed under the terms and conditions of the Creative Commons Attribution (CC BY) license (https:// creativecommons.org/licenses/by/ $4.0 /)$.
6 Department of Endocrinology and Metabolism, Evaggelismos General Hospital, 45-47 Ypsilantou Street, 10676 Athens, Greece; theodorastratigou@yahoo.gr

* Correspondence: natalia.vallianou@hotmail.com; Tel.: +30-21-0720-1414

Abstract: Non-alcoholic fatty liver disease (NAFLD) is the most common chronic liver disease worldwide. NAFLD begins as a relatively benign hepatic steatosis which can evolve to non-alcoholic steatohepatitis (NASH); the risk of cirrhosis and hepatocellular carcinoma (HCC) increases when fibrosis is present. NAFLD represents a complex process implicating numerous factors-genetic, metabolic, and dietary - intertwined in a multi-hit etiopathogenetic model. Recent data have highlighted the role of gut dysbiosis, which may render the bowel more permeable, leading to increased free fatty acid absorption, bacterial migration, and a parallel release of toxic bacterial products, lipopolysaccharide (LPS), and proinflammatory cytokines that initiate and sustain inflammation. Although gut dysbiosis is present in each disease stage, there is currently no single microbial signature to distinguish or predict which patients will evolve from NAFLD to NASH and HCC. Using 16S rRNA sequencing, the majority of patients with NAFLD/NASH exhibit increased numbers of Bacteroidetes and differences in the presence of Firmicutes, resulting in a decreased F/B ratio in most studies. They also present an increased proportion of species belonging to Clostridium, Anaerobacter, Streptococcus, Escherichia, and Lactobacillus, whereas Oscillibacter, Flavonifaractor, Odoribacter, and Alistipes spp. are less prominent. In comparison to healthy controls, patients with NASH show a higher abundance of Proteobacteria, Enterobacteriaceae, and Escherichia spp., while Faecalibacterium prausnitzii and Akkermansia muciniphila are diminished. Children with NAFLD/NASH have a decreased proportion of Oscillospira spp. accompanied by an elevated proportion of Dorea, Blautia, Prevotella copri, and Ruminococcus spp. Gut microbiota composition may vary between population groups and different stages of NAFLD, making any conclusive or causative claims about gut microbiota profiles in NAFLD patients challenging. Moreover, various metabolites may be involved in the pathogenesis of NAFLD, such as short-chain fatty acids, lipopolysaccharide, bile acids, choline and trimethylamine-N-oxide, and ammonia. In this review, we summarize the role of the gut microbiome and metabolites in NAFLD pathogenesis, and we discuss potential preventive and therapeutic interventions related to the gut microbiome, such as the administration of probiotics, prebiotics, synbiotics, antibiotics, and bacteriophages, as well as the contribution of bariatric surgery and fecal microbiota transplantation in the therapeutic armamentarium against NAFLD. Larger and longer-term prospective studies, including well-defined cohorts as well as a multi-omics approach, are required to better identify the associations between the gut microbiome, microbial metabolites, and NAFLD occurrence and progression. 
Keywords: microbiota; multi-omics; NAFLD; NASH; probiotics; prebiotics; bacteriophage

\section{Introduction}

Non-alcoholic fatty liver disease, also known as NAFLD, affects approximately $80-100$ million people or approximately $25 \%$ of the total adult population in the United States. NAFLD is currently the most common cause of chronic liver disease worldwide [1,2]. It is defined as liver steatosis, i.e., an accumulation of fat in the liver exceeding $5 \%$ of the liver's total weight, in the absence of significant alcohol consumption [2]. The overall global prevalence of NAFLD revealed by abdominal imaging is estimated at $25 \%$, with the lowest prevalence in Africa (13.5\%) and the highest in the Middle East (31.8\%) [2]. About $30 \%$ of patients with NAFLD progress to non-alcoholic steatohepatitis (NASH), which is characterized by steatosis with the addition of infiltration by inflammatory cells and different stages of fibrosis (F), ranging from F0 (no fibrosis) to F4 (cirrhosis) [2,3]. The overall prevalence of NASH is approximately between $1.5-6.5 \%$ in the US adult population [2]. NASH may reverse to simple steatosis or may worsen to cirrhosis or even hepatocellular carcinoma (HCC) [3,4]. NAFLD progression and staging are depicted in Figure 1. HCC constitutes the fifth most common cancer in men and the second cause of cancer-related deaths worldwide $[5,6]$. HCC has an estimated incidence of $1-2 \%$ per year among patients with NASH and cirrhosis [6,7]. Moreover, NAFLD may increase cardiovascular risk, being also linked to higher rates of chronic kidney disease and its progression [1-3]. Besides adults, NAFLD and NASH are also rising among adolescents, in parallel with obesity, and are expected to haunt the forthcoming generations in the future $[8,9]$.

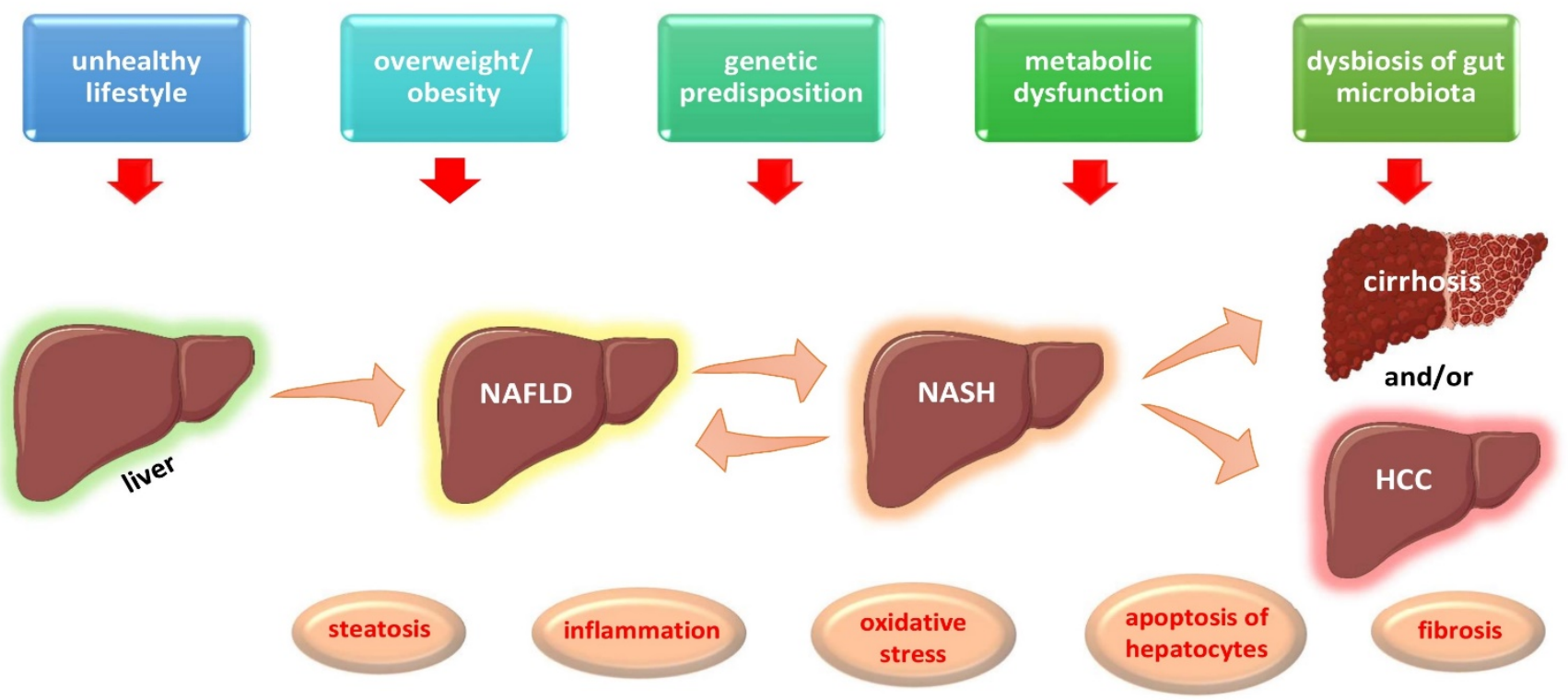

Figure 1. Multi-hit etiopathogenetic model of NAFLD progression and staging. Abbreviations: HCC, Hepatocellular Carcinoma; NAFLD, Non-Alcoholic Fatty Liver Disease; NASH, Non-Alcoholic Steatohepatitis. (All images are originated from the free medical website http:/ / smart.servier.com/ by Servier licensed under a Creative Commons Attribution 3.0 Unported License, accessed on 1 October 2021).

NAFLD and NASH have been associated with a plethora of metabolic risk factors, such as overweight/obesity, type 2 diabetes mellitus (T2DM), prediabetes, hypertension, and dyslipidemia [2]. Lately, expert panels have proposed a change in the nomenclature of NAFLD, which overemphasizes the absence of alcohol and underemphasizes the role of multiple metabolic factors, to metabolic (dysfunction)-associated fatty liver disease 
(MAFLD) [10]. MAFLD is characterized by hepatic steatosis combined with the presence of overweight/obesity or T2DM or at least two of the following metabolic risk factors: (1) waist circumference $\geq 102 \mathrm{~cm}$ in men or $\geq 88 \mathrm{~cm}$ in women or $\geq 90 / 80$ among those of Asian descent; (2) triglyceride (TG) concentration $\geq 150 \mathrm{mg} / \mathrm{dL}$ or treatment for hypertriglyceridemia; (3) high-density lipoprotein cholesterol concentration $<40 \mathrm{mg} / \mathrm{dL}$ in men and $<50 \mathrm{mg} / \mathrm{dL}$ in women or medication for dyslipidemia; (4) systolic blood pressure $\geq 130 \mathrm{~mm} \mathrm{Hg}$ or diastolic pressure $\geq 85 \mathrm{mmHg}$ or treatment for arterial hypertension; (5) homeostasis model assessment of insulin resistance (HOMA-IR) $\geq 2.5$; and (6) C-reactive protein concentration $>2 \mathrm{mg} / \mathrm{L}$ [10]. Although changes in the nomenclature may mirror the pathophysiology of this disorder, they could cause ambiguity as NAFLD is considered a heterogeneous disorder not invariably related to the presence of metabolic syndrome [1]. Interestingly, NAFLD may also be present in individuals without obesity [11]. Indeed, in a recent meta-analysis, around $40 \%$ of the global NAFLD population was categorized as non-obese and almost a fifth was lean (normal body weight) [11].

The prevalence and severity of NAFLD increases with age, reaching a peak at the ages between 45 and 64 years. NAFLD is more frequent in men than women in Caucasian subjects [11]. NAFLD and NASH are clinical entities that have a genetic predisposition and epigenetic components $[12,13]$. The pathogenesis of NAFLD represents a complex process implicating numerous factors-genetic, metabolic, and dietary-intertwined in a multi-hit etiopathogenetic model, as shown in Figure 1. Several studies have pointed out the role of specific genes, such as patatin-like phospholipase containing 3 gene (PNPA3), farnesyl-diphosphate farnesyl transferase 1 gene (FDFT1), transmembrane 6 superfamily protein 2 gene (TM6SF2), glucokinase regulator gene (GCKR), and membrane bound $\mathrm{O}$ acyltransferase domain containing 7 gene (MBOAT7), in the development and progression of NAFLD to NASH and HCC [12-18]. Furthermore, the familial clustering of cases of NAFLD has been reported $[19,20]$. Numerous environmental factors, such as high-fat-diets, diets rich in fructose- and simple-sugar-containing beverages, and diets low in omega- 3 and omega- 6 unsaturated fatty acids, in conjunction with a sedentary lifestyle and a low level of physical activity, have been implicated in the development and progression of NAFLD [21-26]. Recent data have also highlighted the role of the gut metagenome in the etiopathogenesis of NAFLD.

The human microbiome comprises the sum of each and every gene from the bacteria, archaea, viruses, and eukaryotic microbes that inhabit the human body, most of which reside in the gut. The adult gut bacteria belong mainly to two phyla, the Gram-positive Firmicutes and the Gram-negative Bacteroidetes, while Actinobacteria, Proteobacteria, Fusobacteria, and Verrucomicrobia are less frequently encountered in comparison with Firmicutes and Bacteroidetes [27]. There is accumulating evidence that the gut microbiota plays a key role in physiological homeostasis by coordinating immune system reactions by means of modulating the microenvironment in the gut. However, changes in the gut microbiota due to genetic or environmental factors, such as nutritional features or medications, e.g., antibiotics or non-steroid anti-inflammatory drugs, may result in the modulation of the structure or diversity of the gut microbiota, known as dysbiosis [27,28]. In turn, dysbiosis may lead to metabolic derangement, such as T2DM, obesity, the metabolic syndrome, and NAFLD [28,29].

The aim of the present review is to: (1) summarize the role of the gut microbiome in NAFLD pathogenesis; (2) shed light on the distinct microorganisms that seem to be predominant in NAFLD and their metabolic signatures; and (3) provide insight into the potential preventive and therapeutic interventions related to gut microbiota, such as the administration of probiotics, especially next-generation probiotics, e.g., Akkermansia muciniphila and Faecalibacterium prausnitzii, prebiotics, or synbiotics, as well as highlight the contribution of bariatric surgery, bacteriophages, and fecal microbiota transplantation (FMT) in the therapeutic armamentarium against NAFLD. 


\section{NAFLD, Gut Dysbiosis, and Microbial Signatures}

NAFLD is characterized by the accumulation of fat in the form of TG in hepatocytes. Hepatic TGs are formed from the esterification of fatty acids in the liver. The main sources of fatty acids for the liver are the systemic plasma free fatty acids (FFAs), originating from the lipolysis of the adipose tissue TG, and fatty acids synthesized de novo in the liver from simpler precursors, e.g., carbohydrates (lipogenesis) [30]. Gut dysbiosis, which refers to translocation, may render the bowel more permeable, leading to an increased fatty acid absorption. This increased gut permeability may result in bacterial migration via the gut epithelial barrier, with a parallel release of toxic bacterial products, lipopolysaccharides (LPS), and proinflammatory cytokines, which can initiate and sustain inflammation. This process is facilitated by the activation of Nuclear-Factor-kappa-B (NF- $\mathrm{KB}$ ) through the Toll-like receptor 4 (TLR-4) in the host cells. Moreover, the stimulation of TLR4 may induce changes in cellular metabolism associated with fatty-acid-activated inflammation. The hepatic tissue is very sensitive to this process as it filters out a significant portion of the blood coming in through the portal vein (gut-liver axis). Intestinal microbiota could also alter bile acid metabolism, contributing to the pathogenesis of NAFLD by modulating farnesoid X receptor (FXR) stimulation and thus affecting fat and glucose homeostasis [31].

Patients with NAFLD and especially NASH have been shown to exhibit an increased number of Bacteroidetes and differences in the presence of Firmicutes, resulting in a decreased F/B ratio in most studies [9]. Notably, the F/B ratio may vary and not yield consistent results in all studies as it highly depends on the molecular methods used to identify the bacteria, i.e., $16 \mathrm{~S}$ rRNA versus shotgun metagenome sequencing. Moreover, there are huge diversities in the microorganisms within each of these phyla, which renders the F/B ratio a rather crude estimate. Furthermore, these disturbances in the F/B ratio have not been documented among patients with HCC. Apart from this difference, patients with NAFLD have also been demonstrated to exhibit an increased proportion of species belonging to Clostridium, Anaerobacter, Streptococcus, Escherichia, and Lactobacillus, whereas Oscillibacter, Flavonifaractor, Odoribacter, and Alistipes spp. are less prominent [32]. Besides, there is a relative abundance of potential pathogens, such as Gram-negative Proteobacteria, Enterobacteriaceae, and Escherichia spp. among patients with NASH, when compared to healthy controls, while Faecalibacterium prausnitzii and Akkermansia muciniphila are relatively diminished [33-35]. Faecalibacterium prausnitzii, a Gram-positive anaerobe bacterium, Eubacterium rectale, Eubacterium halii, and Anaerostipes caccae are well-known short-chain fatty acids (SCFAs) producers, particularly butyrate. Akkermansia muciniphila, a mucin-producing, Gram-negative anaerobe bacterium, when co-cultured with the butyrateproducing Faecalibacterium prausnitzii, Eubacterium rectale, Eubacterium halii, and Anaerostipes caccae results in an enhanced production of butyrate. Therefore, Akkermansia muciniphila, apart from its beneficial role in the gut epithelium per se, may promote the growth of other bacteria with anti-inflammatory properties [33-35]. Children with NAFLD and NASH have a decreased proportion of Oscillospira spp. accompanied by an elevated proportion of Dorea, Blautia, Prevotella copri, and Ruminococcus spp. when compared to healthy controls [36]. Figure 2 shows the altered gut microbiota found in patients with NAFLD/NASH. Table 1 depicts major studies in animal models, while Table 2 portrays major studies in humans regarding the gut microbiota signatures in NAFLD. 


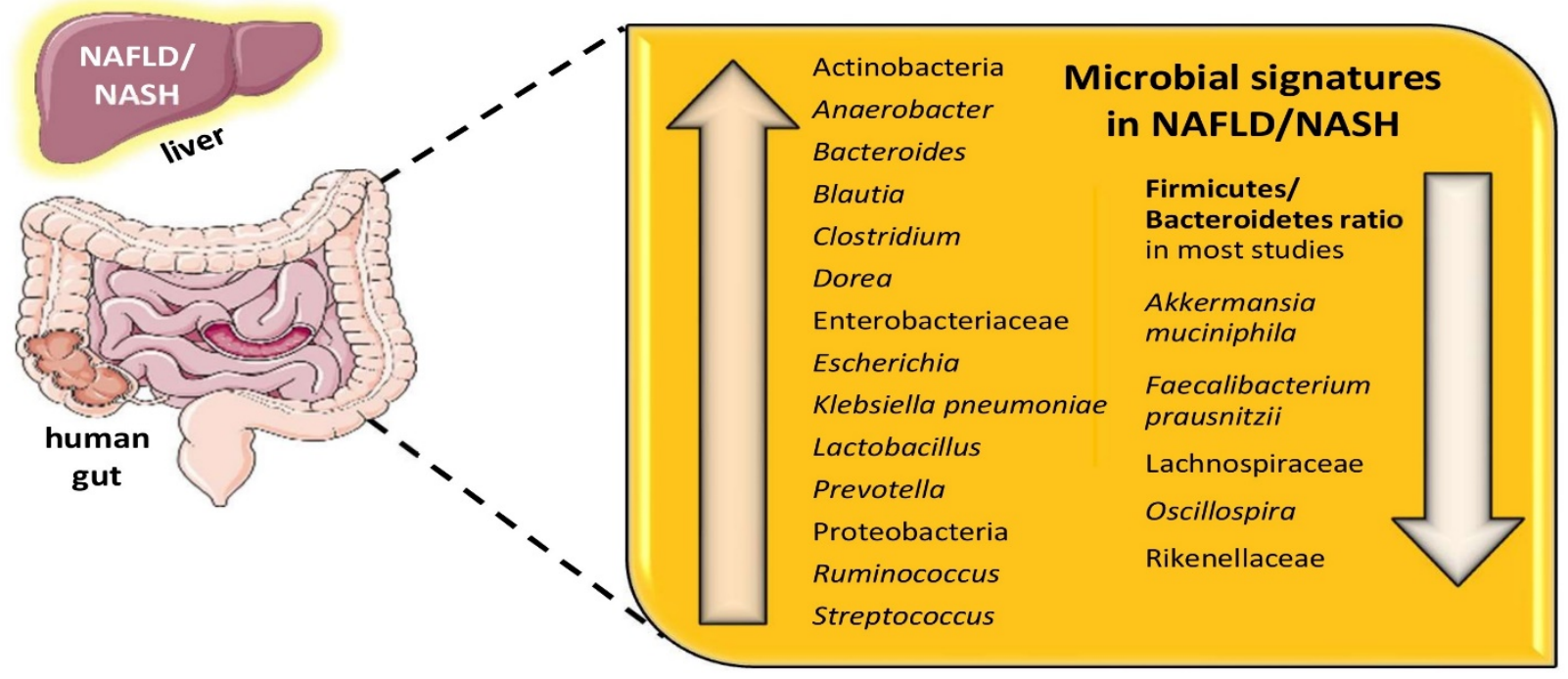

Figure 2. Gut microbial signatures found in NAFLD/NASH. Abbreviations: NAFLD, Non-Alcoholic Fatty Liver Disease; NASH, Non-Alcoholic Steatohepatitis. (All images are originated from the free medical website http://smart.servier.com/ by Servier licensed under a Creative Commons Attribution 3.0 Unported License, accessed on 1 October 2021).

The alteration in the gut microbiota is related to higher fecal concentrations of 2butanone and 4-methyl-2-pentanone, metabolites known to cause hepatocellular toxicity in individuals with metabolic liver diseases, when compared to healthy individuals [37]. In addition, due to the fact that the gut microbiota in patients with NALFD is enriched in ethanol-producing bacteria, such as E. coli, which is capable of producing ethanol under anaerobe conditions, it has been suggested that this rich gut microbiota may produce more ethanol than the microbiota of healthy individuals, as evidenced by the increased concentrations of intrinsically generated ethanol in the circulation as well as in the breath $[33,37]$. Ethanol is known to stimulate NF- $\kappa B$ signaling molecules to provoke tissue damage, via impairing gut barrier function and, thus, contributing to increased portal LPS concentrations $[38,39]$. It has been documented that the detoxification pathway is weakened in the liver of patients with NALFD, resulting in an increased production of reactive oxygen species (ROS), which have the potential to cause oxidative damage to the hepatocytes, resulting in augmented hepatic inflammation and subsequently contributing to NASH [40]. Results from the scarce human and animal fecal transplantation studies found a higher abundance of the alcohol-producing bacterial species Klebsiella pneumoniae in the gut, which led to acceleration in the pathogenesis of NAFLD [41-43]. 
Table 1. Differences in microbial species abundance in various animal models.

\begin{tabular}{|c|c|c|}
\hline \multicolumn{3}{|c|}{ Animal Studies } \\
\hline Study, Year & Animal Model & Remarks \\
\hline Rahman et al., 2016 [44] & $\begin{array}{l}\text { Knockout mice of the F11 receptor gene, a gene } \\
\text { conferring a junctional adhesion molecule A, } \\
\text { implicated in derangement in intestinal permeability }\end{array}$ & $\begin{array}{l}\uparrow \text { Firmicutes } \\
\uparrow \text { Proteobacteria }\end{array}$ \\
\hline Pierantonelli et al., 2017 [45] & NLRP3 Knockout mice & $\begin{array}{c}\downarrow \text { Gram negative species } \\
\downarrow \text { Bacterial translocation after treatment } \\
\text { with antibiotics }\end{array}$ \\
\hline Llorente et al., 2017 [46] & Sublytic Atp4aSl/Sl mice treated with PPIs & $\uparrow$ Enterococcus faecalis with PPIs \\
\hline Gart et al., 2018 [47] & Leiden mice & Variations in gut microbiota, non-specific \\
\hline Schneider et al., 2019 [48] & $\begin{array}{l}\text { Rats with methionine-choline deficient diet-induced } \\
\text { NASH }\end{array}$ & $\downarrow$ Gut microbiota diversity \\
\hline Petrov et al., 2019 [49] & GF-HFD not responders & $\begin{array}{l}\uparrow \text { Desulfovibrio } \\
\uparrow \text { Oscillospira } \\
\downarrow \text { Bacteroides } \\
\downarrow \text { Oribacterium }\end{array}$ \\
\hline Chen et al., 2019 [50] & Knockout SIRT3 HFD mice & $\begin{array}{l}\uparrow \text { Desulfovibrio } \\
\downarrow \text { Oscillibacter } \\
\downarrow \text { Alloprevotella }\end{array}$ \\
\hline De Sant'Ana et al., 2019 [51] & Knockout mice (caspases 1/11 and NLRP3 HFD) & $\begin{array}{l}\uparrow \text { Proteobacteria } \\
\uparrow \mathrm{F} / \mathrm{B} \text { ratio }\end{array}$ \\
\hline Ahmad et al., 2020 [52] & Mice C57BL/6J HFD & $\begin{array}{l}\text { Alterations in Prevotellaceae UCG-003, } \\
\text { Ruminococcaceae UCG-005, Desulfovibrio, } \\
\text { the Lachnospiraceae NK4A136 group, } \\
\text { Lactobacillus and Akkermansia }\end{array}$ \\
\hline Cavallari et al., 2020 [53] & NOD2 Knockout mice & $\begin{array}{c}\uparrow \text { Clostridiales } \\
\downarrow \text { Erysipelotrichaceae }\end{array}$ \\
\hline Zhang et al., 2021 [54] & Mice, C57BL/6 male, high-fat, high-cholesterol diet & $\begin{array}{c}\uparrow \text { Mucispirillum } \\
\uparrow \text { Desulfovibrio } \\
\uparrow \text { Anaerotruncus } \\
\uparrow \text { Desulfovibrionaceae } \\
\downarrow \text { Bifidobacterium } \\
\downarrow \text { Bacteroides }\end{array}$ \\
\hline
\end{tabular}

Abbreviations: F/B ratio: Firmicutes to Bacteroidetes ratio; GF: Germ Free; HFCD: High-Fat, High-Cholesterol Diet, HFD I: High-Fat Diet; $\uparrow:$ increased, $\downarrow$ : decreased. 
Table 2. Evidence from human studies depicting associations of various bacterial species and metabolic signatures in patients with NAFLD.

\begin{tabular}{|c|c|c|c|c|}
\hline \multicolumn{5}{|c|}{ Human Studies } \\
\hline Study, Year & Population & Lab Techniques & Microbiome & Remarks \\
\hline Belgaumkar et al., 2016 [55] & $\begin{array}{c}\text { NAFLD as described by serum } \\
\text { cytokeratin } 18, \\
18 \text { patients who underwent } \\
\text { laparoscopic sleeve gastrectomy } \\
\text { (UK) }\end{array}$ & $\begin{array}{l}\text { Serum: Liquid chromatography } \\
\text { tandem-mass spectometry for BA }\end{array}$ & No bacteria were further detected & $\begin{array}{c}\text { Total BA did not change; } \\
\downarrow \text { primary glycine- and } \\
\text { taurine-conjugated BA, } \\
\downarrow \text { cholic acid, and } \\
\uparrow \text { secondary BA, } \\
\uparrow \text { glycine-conjugated } \\
\text { urodeoxycholic acid over the study } \\
\text { period. These changes are associated } \\
\text { with reduction in insulin resistance, } \\
\text { pro-inflammatory cytokines, and CK-18 } \\
\text { levels }\end{array}$ \\
\hline Boursier et al., 2016 [56] & $\begin{array}{c}\text { Biopsy-proven NAFLD among } \\
57 \text { patients } \\
\text { (France, USA) }\end{array}$ & $\begin{array}{l}\text { Fecal Microbiome: } 16 S \text { rRNA gene } \\
\text { Sequencing }\end{array}$ & $\begin{array}{c}\text { Patients with NASH and F2 } \geq 2 \text { : } \\
\uparrow \text { Bacteroides } \\
\downarrow \text { Prevotella. } \\
\text { Patients with } \mathrm{F} 2 \geq 2 \text { : } \\
\uparrow \uparrow \text { Ruminococcus }\end{array}$ & $\begin{array}{c}\text { NASH was related to } \\
\uparrow \text { Bacteroides, while significant fibrosis to } \\
\uparrow \uparrow \text { Ruminococcus }\end{array}$ \\
\hline Del Chierico et al., 2017 [36] & $\begin{array}{c}\text { NAFLD in } \\
61 \text { patients and } 51 \text { non-NAFLD } \\
\text { controls } \\
\text { (Italy) }\end{array}$ & $\begin{array}{l}\text { Fecal Microbiome: } \\
\text { rRNA Sequencing } \\
\text { Serum metabolites: GC/MS }\end{array}$ & $\begin{array}{c}\text { Patients with NAFLD: } \\
\uparrow \text { Actinobacteria } \\
\downarrow \text { Bacteroidetes } \\
\uparrow \text { Ruminococcus } \\
\uparrow \text { Blautia } \\
\uparrow \text { Dorea } \\
\downarrow \text { Oscillospira } \\
\downarrow \text { Rikenellaceae }\end{array}$ & $\begin{array}{l}\text { Patients with NAFLD: } \\
\uparrow \text { 2-butanone } \\
\uparrow 1 \text {-pentanol } \\
\uparrow \text { 4-methyl-2-pentanone }\end{array}$ \\
\hline
\end{tabular}


Table 2. Cont.

\begin{tabular}{|c|c|c|c|c|}
\hline \multicolumn{5}{|c|}{ Human Studies } \\
\hline Study, Year & Population & Lab Techniques & Microbiome & Remarks \\
\hline Puri et al., 2018 [58] & $\begin{array}{l}\text { Biopsy-proven NAFLD among } \\
86 \text { patients and } 24 \text { non-NAFLD } \\
\text { controls } \\
\text { (USA) }\end{array}$ & Serum metabolites: LC/MS & No bacteria were further detected & $\begin{array}{c}\text { Patients with NAFLD and } \geq \mathrm{F} 2 \text { : } \\
\uparrow \text { conjugated cholate } \\
\downarrow \text { ratio of total secondary to primary } \\
\text { BAs } \\
\text { Patients with NASH had } \\
\uparrow \uparrow \text { total conjugated primary BAs when } \\
\text { compared to controls }\end{array}$ \\
\hline Hoyles et al., 2018 [59] & $\begin{array}{c}\text { Biopsy-proven NAFLD among } 56 \\
\text { patients } \\
\text { (UK, Italy, France) }\end{array}$ & $\begin{array}{c}\text { Fecal Microbiome: } \\
\text { Shotgun Metagenomic Sequencing } \\
\text { Serum and urine metabolites: } \\
\text { LC/MS }\end{array}$ & $\begin{array}{c}\text { Among patients with steatosis: } \\
\uparrow \text { Proteobacteria } \\
\uparrow \text { Actinobacteria }\end{array}$ & $\begin{array}{c}\text { Among patients with steatosis: } \\
\text {-Serum BCAAs: } \\
\uparrow \text { leucine } \\
\uparrow \text { valine } \\
\uparrow \text { isoleucine } \\
\uparrow \text { phenylacetic acid } \\
\text {-Urine: } \\
\uparrow \text { choline }\end{array}$ \\
\hline Caussy et al., 2018 [60] & $\begin{array}{l}\text { Discovery cohort of } 156 \text { twins } \\
\text { Validation cohort of Biopsy-proven } \\
\text { NAFLD among } \\
156 \text { patients } \\
\text { (USA, France) }\end{array}$ & $\begin{array}{c}\text { Fecal Microbiome: Whole Shotgun } \\
\text { Metagenomics Sequencing } \\
\text { Liver: MRI-PDFF; MRE } \\
\text { Serum metabolites: LC/MS; } \\
\text { GC/MS }\end{array}$ & $\begin{array}{c}\text { Patients with NAFLD and }>\text { F2: } \\
\uparrow \text { Furmicutes } \\
\uparrow \text { Bacteroidetes } \\
\uparrow \text { Proteobacteria }\end{array}$ & $\begin{array}{c}56 \text { metabolites had a relationship with } \\
\text { hepatic fibrosis, among which } \\
\text { 3-(4-hydroxyphenyl) lactate, } \\
\mathrm{N} \text {-formylmethionine, phenyllactate, } \\
\text { mannitol, allantoine and N-(2-furoyl) } \\
\text { glycine were the most abundant } \\
\text { 3-(4-hydroxyphenyl) lactate was } \\
\uparrow \uparrow \text { in liver fibrosis and steatosis }\end{array}$ \\
\hline Caussy et al., 2019 [61] & $\begin{array}{c}\text { Cross-sectional; } \\
203 \text { participants including NAFLD } \\
\text { and healthy controls } \\
\text { (USA) }\end{array}$ & $\begin{array}{c}\text { Fecal Microbiome: } 16 \mathrm{~S} \text { rRNA } \\
\text { Sequencing } \\
\text { Liver: MRI/MRE }\end{array}$ & $\begin{array}{c}\text { Patients with NAFLD and cirrhosis: } \\
\uparrow \text { Enterobacteriaceae } \\
\uparrow \text { Streptococcus } \\
\uparrow \text { Gallibacterium } \\
\uparrow \text { Megasphaera } \\
\text { A trend towards Gram negative } \\
\text { species in advanced fibrosis was } \\
\text { reported }\end{array}$ & No metabolites were further detected \\
\hline
\end{tabular}


Table 2. Cont.

\begin{tabular}{|c|c|c|c|c|}
\hline \multicolumn{5}{|c|}{ Human Studies } \\
\hline Study, Year & Population & Lab Techniques & Microbiome & Remarks \\
\hline Lee et al., 2020 [62] & $\begin{array}{c}\text { Biopsy-proven NAFLD among } \\
171 \text { patients and } 31 \text { non-NAFLD } \\
\text { controls } \\
\text { (USA, Korea) }\end{array}$ & $\begin{array}{l}\text { Fecal Microbiome: } 16 S \text { rRNA } \\
\text { Sequencing }\end{array}$ & $\begin{array}{c}\text { Patients with NAFLD and >F2, } \\
\text { non-obese: } \\
\uparrow \text { Ruminococcaceae } \\
\uparrow \text { Veillonellaceae }\end{array}$ & $\begin{array}{c}\text { Patients with NAFLD and }>\mathrm{F} 2, \\
\text { non-obese: } \\
\uparrow \text { BA } \\
\uparrow \text { Propionate in feces }\end{array}$ \\
\hline Adams et al., 2020 [63] & $\begin{array}{l}\text { Biopsy-proven NAFLD among } \\
67 \text { patients and } 55 \text { non-NAFLD } \\
\text { controls } \\
\text { (USA) }\end{array}$ & $\begin{array}{c}\text { Fecal Microbiome: } \\
\text { 16S rRNA Sequencing } \\
\text { Serum and fecal metabolites: } \\
\text { HPLC/MS }\end{array}$ & $\begin{array}{c}\text { Patients with NAFLD and >F2: } \\
\uparrow \text { Firmicutes } \\
\uparrow \text { Proteobacteria } \\
\uparrow \text { Actinobacteria } \\
\downarrow \text { Bacteriodetes } \\
\uparrow \text { Actinomycetaceae } \\
\downarrow \text { Lachnospiraceae }\end{array}$ & $\begin{array}{l}\text { Patients with NAFLD and >F2: } \\
\uparrow \text { BA in serum and feces }\end{array}$ \\
\hline Masarone et al., 2021 [64] & $\begin{array}{c}\text { Biopsy-proven NAFLD among } \\
144 \text { patients } \\
\text { (Italy) }\end{array}$ & Serum metabolites: GC/MS & $\begin{array}{l}\text { No bacteria were } \\
\text { further detected }\end{array}$ & $\begin{array}{c}\text { Patients with NAFLD } \\
\text { and }>\text { F2: } \\
\uparrow \text { Glycocholic acid } \\
\uparrow \text { Taurocholic acid } \\
\uparrow \text { Phenylalanine } \\
\uparrow \text { BCAAs } \\
\downarrow \text { Glutathione }\end{array}$ \\
\hline Nimer et al., 2021 [65] & $\begin{array}{l}\text { Biopsy-proven NAFLD among } \\
102 \text { patients and } 50 \text { non-NAFLD } \\
\text { controls } \\
\text { (USA) }\end{array}$ & Plasma BA metabolites: LC/MS & $\begin{array}{l}\text { No bacteria were } \\
\text { further detected }\end{array}$ & $\begin{array}{c}\text { Patients with NAFLD } \\
\text { and }>\text { F2: } \\
\uparrow \uparrow \text { Plasma 7-keto-DCA levels } \\
\text { Some glycine conjugated forms of BAs } \\
\uparrow \uparrow \text { in more advanced stages of NAFLD }\end{array}$ \\
\hline
\end{tabular}


Animal studies have yielded different results regarding the microbial species in models with NAFLD. These differences may be attributed to the different animal models used, i.e., differences in the knock-out mice and deleted genes. However, most studies have documented a state of gut dysbiosis in NAFLD [44-54]. Overall, human studies have found differential abundances among patients with NAFLD and especially among patients with severe NAFLD associated with fibrosis-and particularly among those staged $\geq F 2$. A variety of changes in the abundance of Bacteroidetes, Firmicutes, and especially Ruminococcus has been observed, with either increases or decreases in the relative abundances of the abovementioned species. These differences may be attributed to several reasons, mainly the different molecular techniques used to describe bacteria to the species level and the differences in the methodologies used for the definition of NAFLD and especially NASH. Regarding molecular techniques for the description of the gut microbiota, methods such as the Polymerase Chain Reaction (PCR) and the 16S rRNA gene amplicon sequencing and Next-Generation Sequencing (NGS), such as the shotgun metagenome sequencing, have shed light on the abundance of different species in the gut microbiota of patients with NAFLD/NASH/HCC. However, it is exactly the advent of differences in the methodologies used for DNA extraction, PCR, and NGS techniques which may contribute to the variability in the relative abundances of the different species found. In addition, the site from which the specimen has been acquired, e.g., rectum or caecum, as well as the type of specimen, e.g., feces versus biopsy specimen, may account for the reported differences in the isolated microbiota species. Regarding the diagnosis and staging of NAFLD/NASH, the gold standard remains the liver biopsy. Nevertheless, a plethora of imaging techniques, such as ultrasound, contrast ultrasound, computed tomography, magnetic resonance imaging, ultrasound elastography, and magnetic resonance elastography, in conjunction with several noninvasive biomarkers, are commonly used instead of a liver biopsy due to their availability and safety. Liver biopsy is an invasive and expensive diagnostic method, critically depending on the experience of the physician and increasing the risk of complications. Therefore, human studies have the drawback of using different molecular techniques and, moreover, different diagnostic methodologies to characterize patients with NAFLD/NASH. These differences may account for the differential abundances of bacterial species of the gut microbiota among patients with NAFLD/NASH [36,55-65]. Further large-scale, homogeneous, and longitudinal studies are needed to further categorize the microbial signatures of patients with NAFLD/NASH.

\section{Microbiome-Derived Compounds in the Pathogenesis of NAFLD}

Various metabolites have been implicated in the pathogenesis of NAFLD, such as short-chain fatty acids, LPS, bile acids, choline and trimethylamine-N-oxide, and ammonia levels. The abovementioned substances have all been involved in the etiopathogenesis of NAFLD, as portrayed in Figure 3.

SCFAs act by promoting intestinal integrity, whereas the LPS has a negative effect on this functional barrier. Differences in bile acids may also affect the dynamics of their portal circulation, thereby influencing NAFLD development, while choline deficiency has been related to a reduced hepatic production of very-low-density lipoproteins (VLDL), resulting in the accumulation of TG within the liver, thus promoting NAFLD. Ammonia is a marker of hepatic encephalopathy but is also suggested to be involved in the pathogenetic mechanisms of NAFLD. 


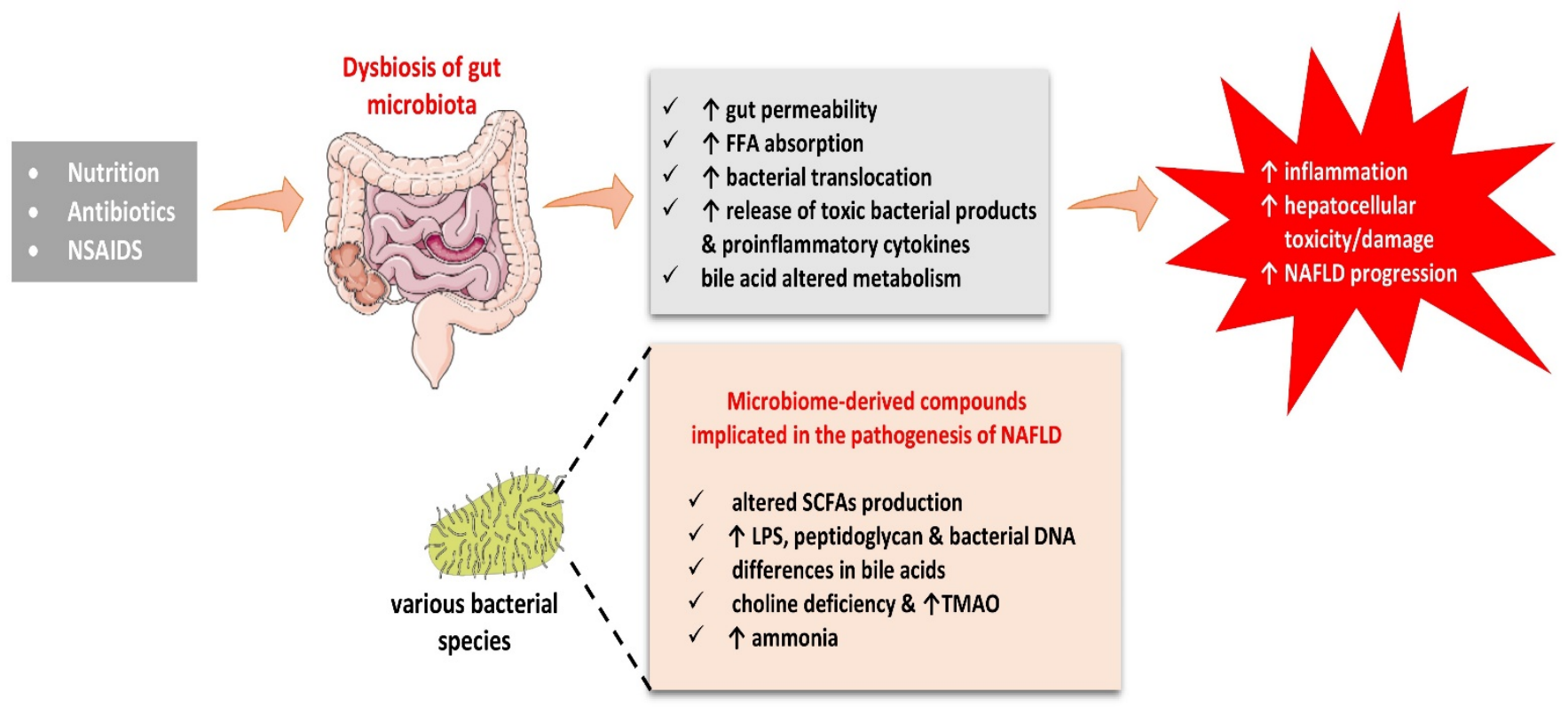

Figure 3. Dysbiosis of gut microbiota may explain the inflammatory process and hepatotoxicity of microbiome-derived compounds implicated in the pathogenesis of NAFLD. Abbreviations: FFA, Free Fatty Acids; LPS, Lipopolysaccharide; NAFLD, Non-Alcoholic Fatty Liver Disease; NSAIDs, Non-Steroid Anti-Inflammatory Drugs; SCFAs, Short-chain Fatty Acids; TMAO, Trimethylamine Noxide. (All images are originated from the free medical website http:/ / smart.servier.com/ by Servier licensed under a Creative Commons Attribution 3.0 Unported License, accessed on 1 October 2021).

\subsection{SCFAs}

SCFAs, mainly acetate, propionate, and butyrate are organic fatty acids synthesized from non-digestible proteins and fibers via anaerobic fermentation by the gut microbiota $[66,67]$. They are mainly produced in the distal colon, where they serve as a complementary factor to intestinal integrity and function. SCFAs are transferred to the liver by means of the portal circulation, thereby serving as precursors for gluconeogenesis and lipogenesis $[68,69]$. In fact, SCFAs are responsible for about $5-10 \%$ of the typical energy demands under normal conditions [70,71]. There are numerous studies demonstrating that SCFAs activate the G-protein-coupled receptors (GPCRs) GPR41 and GPR43 in the surface of the gut enteroendocrine L cells. In particular, activation of the GPCRs stimulates peptide YY (PYY) release, which results in the slowing down of gastric emptying and the promotion satiety [72,73]. In addition, activation of GPR41 and GPR43 on the surface of the L cells increases secretion of GLP-1, an incretin known to slow gastric emptying and induce satiety, thus decreasing food intake. Furthermore, GLP-1 enhances lipid oxidation in the liver, which contributes to diminished steatosis [73-76]. Besides their functionality as energy substrates, SCFAs have the potential to affect hepatic metabolism by functioning as signaling molecules. In particular, propionate and butyrate activate AMP-activated protein kinase (AMPK) to promote hepatic autophagy, a catabolic process which results in the hydrolysis of TG and the release of fatty acids for $\beta$-oxidation in the mitochondria [76-80]. The activation of AMPK by SCFAs has been related to increased Uncoupling Protein 2 (UCP2) levels and an increased AMP:ATP ratio [81]. Apart from the AMPK activation, SCFAs inhibit class I and II histone deacetylases and can thus alter gene transcription. Class I and II histone deacetylases are enzymes which catalyze the removal of acetyl groups from lysine residues on histones to reduce gene transcription. Butyrate and propionate have been shown to inhibit histone deacetylases in human colon carcinoma cells, whilst in macrophages the inhibitory effect of butyrate on histone deacetylases is likely to be responsible for its anti-inflammatory properties [76-81]. Loomba et al. have reported that patients with advanced fibrosis have increased acetate levels in their fecal samples, whereas patients with mild or moderate NAFLD presented increased levels of butyrate and 
propionate [20]. However, when circulating SCFAs were measured in cirrhosis patients the serum butyric acid levels inversely correlated to the inflammatory markers and serum endotoxin levels [76-80]. These differences may be attributed to a plethora of factors, such as variations in age, diet, environmental parameters, or even sample handling and processing. More specifically, the estimation of serum or fecal SCFA levels is troublesome per se as SCFAs are volatile substances, requiring immediate processing for an accurate measurement. However, SCFA supplementation in mouse models of NAFLD has shown beneficial effects. In High Fat Diet (HFD)-fed rodents, supplementation with butyrate resulted in a reduction in liver and adipose tissue inflammation. Besides, butyrate promoted alterations in the bacterial population of the gut microbiota. In particular, it enhanced SCFA-producing bacteria and reduced endotoxin-releasing bacteria [82]. Based on these animal model data, SCFA supplementation may have beneficial metabolic effects as well as decrease the severity of liver steatosis. Large-scale studies of SCFA supplementation among patients with NAFLD are lacking. It would be really intriguing to investigate SCFA supplementation in RCTs in humans.

\subsection{Endotoxins}

Inflammation is a hallmark feature of NASH, in which gut microbiota play a pivotal role [83]. Bacterial products stemming from gut microbiota, such as LPS, peptidoglycan, and bacterial DNA, may be transferred via the portal vein to activate the TLRs on Kupffer cells, leading to an inflammatory cascade which promotes the development of NASH. Elevated levels of LPS have been detected in NAFLD in rodent (rats and mice) and human studies [84-86]. Pathogen-associated molecular pattern (PAMP) receptors, such as TLRs, are deeply implicated in the pathogenesis of NASH by the activating of NF- $\mathrm{KB}$, inducing the secretion of chemokines from macrophages, and the recruiting of Kupffer cells to the liver to promote the inflammation process [84-90]. In addition, Nod-like receptor protein (NLRP)-3 may stimulate immunity by means of forming an inflammasome with ACS (the adaptor molecule apoptosis-associated speck-like protein containing a CARD), an apoptosis-associated protein, in order to activate pro-caspase 1 [91]. Inflammasome dysfunction leads to exaggerated liver inflammatory response, liver fibrosis, and cell death [91]. This role of NLRP3 has been documented in HFD-fed rodents, which exhibited decreased liver steatosis by inhibition of the NLRP3 inflammasome pathway [92]. Several TLRs have been shown to be of key importance, with the most significant being TLR-4 and TLR-9. For example, rodents deficient in TLR4 and myeloid-differentiation factor-2 (MD2) are protected from methionine- and choline-deficient diet-induced liver inflammation and liver steatosis [93]. Furthermore, plasma from patients with NASH has been found to possess increased levels of mitochondrial DNA as a potent TLR-9 activator. Mice deficient in TLR9 have been documented to be protected from HFD-induced liver steatosis and inflammation, thus pointing out the importance of the TLR-9 pathway in modulating inflammation in NASH [91-93]. Lastly, TLR-5 may play a protective role in diet-induced NASH, as mice lacking TLR-5 on hepatocytes showed exacerbated disease after being fed with a methionine- and choline-deficient diet [94]. These examples help clarify how PAMPs may provoke inflammation in the liver and suggest an interplay of bacteria and gut microbiota in the pathogenesis of NASH.

\subsection{Bile Acids}

Bile acids (BAs) are mainly produced by cholesterol in the liver. They are categorized as primary BAs, such as cholic acid (CA) and chenodeoxycholic acid (CDCA), and secondary BAs, such as deoxycholic and lithocholic acid $[95,96]$. Primary BAs are further conjugated with glycine or taurine and stored in the gallbladder before being released into the intestine after consumption of a meal. In the gut, BAs are implicated in the absorption of dietary fat, cholesterol, and fat-soluble vitamins $[97,98]$. The primary BAs are deconjugated and dehydroxylated by gut microbiota to the more hydrophobic secondary BAs, which are reabsorbed in the distal ileum and returned to the liver by means of the portal vein [97-99]. 
There are several studies in favor of the notion that there are specific BA profiles related to NASH $[100,101]$. For example, Yara et al. have analyzed serum BAs and have documented that the ratios of primary to secondary BAs, taurine-conjugated BAs to glycine-conjugated BAs, unconjugated BAs to total BAs, and secondary BAs to total BAs are reduced in NASH patients compared to those of healthy individuals [100]. Moreover, Chen et al. have documented that increased ratios of circulating conjugated Chenodeoxycholic acids (CDCAs) to muricholic acids in NASH patients are correlated to the histological severity of NASH and the grade of fibrosis [101]. In addition, a BA intermediate and marker for de novo BAs synthesis, $7 \alpha$-hydroxy-4-cholesten-3-one (C4), has been shown to be increased in the serum of patients with $\mathrm{NASH}$ and has also been related to changes in the gut microbiota [102].

BAs, especially secondary ones, may serve as signaling molecules by binding to cellular receptors, such as the FXR and the G protein-coupled bile acid receptor 1 (also known as TGR5). Different BAs possess variable abilities to activate these receptors [103]. For example, secondary BAs are more potent than primary BAs in activating TGR5 [104]. TGR5 is ubiquitously expressed throughout the human body with increased levels of TGR5 mRNA detected in metabolically active organs, such as the small intestine, stomach, and liver. Activating TGR5 has been shown to increase the intestinal GLP-1 release in obese animal models [104,105]. TGR5 has also been documented to be expressed in monocytes, macrophages, and Kupffer cells, modulating immune responses [104-106]. Indeed, in isolated Kupffer cells, bile acids activated TGR5 and inhibited LPS-induced cytokine expression in a cAMP-dependent manner [104-106]. However, there is a scarcity of studies in animal models as well as in humans regarding the role of BAs in the pathogenesis of NAFLD in animal models as well as in humans.

\subsection{Choline and TMAO}

Choline is mainly obtained from dietary sources, such as red meat, eggs, cheese, and peanuts, although de novo choline synthesis may also take place in the liver [107]. Choline is a component of the cell membrane, necessary for the production of phosphatidylcholine and sphingomyelin, which are indispensable structural and functional membrane phospholipid components. In the liver, choline is also necessary for the production of VLDL. Therefore, choline deficiency may lead to a reduced production of VLDL, resulting in the accumulation of TG in the liver [108,109]. For this reason, choline-deficient diets have been used in animal models to induce NASH [110]. Choline is known to be converted to trimethylamine (TMA) by gut microbiota. TMA can be oxidized by hepatic monooxygenases to produce trimethylamine $\mathrm{N}$-oxide (TMAO) in the liver, which is afterwards released in the systemic circulation [107]. In HFD-fed rodents, higher conversion of choline to TMA by microbiota resulted in lower bioavailability of choline [111]. TMAO may also act directly on the liver and contribute to impaired glucose tolerance and the development of NAFLD [7,112]. In particular, studies have demonstrated that serum levels of TMAO are higher in patients with NAFLD than in healthy controls, being also correlated with the severity of hepatic steatosis [113]. Another study reported that elevated serum TMAO levels are related to NASH in patients with T2DM [114]. TMAO levels have also been associated with atherosclerosis via the increased production of foam cells in animal models. In particular, TMAO has been demonstrated to promote macrophage migration and their transformation into foam cells, while endothelial dysfunction as well as platelets dysfunction and thrombus formation have been correlated to increased TMAO levels. Based on these mechanisms, high blood TMAO has been suggested as a contributor to the increased cardiovascular disease risk. However, it remains unknown whether serum TMAO levels may serve as a biomarker for NAFLD prognosis or other metabolic derangements or whether it may function as a potential therapeutic target for atherosclerosis [115]. 


\subsection{Ammonia}

Hyperammonemia is suggested to be a marker of the severity of liver disease [116]. During NASH, ornithine transcarbamylase and carbamoyl phosphate synthetase mRNA, protein, and activity have been shown to be decreased, leading to hyperammonemia [117]. Notably, ammonia itself has been suggested to exert direct effects on hepatic stellate cells by activating them in cell culture as well as in vivo [118]. The above-mentioned findings suggest that hyperammonemia during NASH and cirrhosis may itself promote fibrosis. Ammonia is also generated from amino acids in the gut by bacteria [119]. Therefore, the composition of the gut microbiota contributes to the circulating ammonia levels. However, the exact amount of ammonia produced by gut microbiota and their role in determining serum ammonia levels in NASH and cirrhosis are not well known.

There is accumulating evidence that NAFLD is related to suboptimal liver function, even during the early stages of the disease [120-123]. Urea synthesis occurs exclusively in the liver, which is the primary location for waste nitrogen, i.e., ammonia elimination, by converting excess amino-nitrogen to urea [124]. This cycle is significantly impaired in patients with cirrhosis due to the loss of function of the hepatic cells, resulting in the accumulation of ammonia [124,125]. However, this cycle appears to be impaired even in the pre-cirrhotic stages of NAFLD. It has been documented-both in animal models as well as in humans with NAFLD - that there is a decrease in the ability for urea synthesis, together with the expression and function of urea cycle enzymes, even at the stage of simple steatosis without fibrosis (F0), which leads to a reduced ammonia elimination and thus hyperammonemia even at a non-cirrhotic stage [117,118,126,127]. Furthermore, dietary intervention resulted in the restoration of the normal urea cycle enzyme activity in animal models of NASH, which was further related to a significant reduction in liver fat content [116,128]. There is mounting evidence arguing that the presence of steatosis has a detrimental effect on mitochondrial liver function, including the urea cycle, while in vitro studies have demonstrated that the accumulation of lipids in hepatocytes leads to reduced expression of the urea cycle enzymes and thus hyperammonemia [116,118,129,130]. Therefore, steatosis in early NAFLD seems to be the cause of dysfunction in the urea cycle rather than just a coincidental finding [131]. Ammonia is a neurotoxic molecule that easily crosses the blood brain barrier and plays a key role in the pathogenesis of hepatic encephalopathy [132]. However, the pathogenesis of hepatic encephalopathy is complicated, and whilst ammonia undoubtedly plays a key role, it is not solely responsible for the neurocognitive dysfunction in hepatic encephalopathy [133]. Many studies have documented that hepatic encephalopathy manifestations may be exacerbated in an inflammatory milieu [134-136]. Therefore, systemic inflammation acts together with the dysfunctional nitrogen metabolism in patients with progressive liver dysfunction. It is widely accepted that hepatic encephalopathy represents a primary gliopathy, which results from astrocyte swelling and oxidative stress. Even in the absence of clinically overt hepatic encephalopathy, low-grade astrocyte swelling, which may be present in NAFLD, could impair the crosstalk between neurons and swollen astrocytes [137-139]. Neuroinflammation is now considered a well-established feature of hepatic encephalopathy [140-145]. It is suggested that neuroinflammation caused by hyperammonemia could be reversible by decreasing systemic ammonia levels or by anti-inflammatory treatment [146].

\section{Therapeutic Interventions Related to Gut Microbiota for NAFLD}

Patients with NAFLD present higher overall morbidity and mortality, attributed mainly to hepatic complications, cardiovascular diseases, and cancer [8]. The therapeutic management of NAFLD is focused on hepatic disease, mainly fibrosis, which is a significant prognostic factor, while also targeting metabolic comorbidities such as obesity, T2DM, and dyslipidemia. The most efficient and significant step for the therapeutic management of NAFLD, recommended by all medical societies, is lifestyle modification through a healthy diet and regular physical activity resulting in weight loss. Interestingly, intensive lifestyle modification ameliorated NAFLD in lean and overweight/obese patients [147]. However, 
lifestyle modifications may be difficult to achieve and maintain. Drug therapy should be directed to patients with NAFLD presented with advanced disease, i.e., NASH with fibrosis, taking into account safety issues and NAFLD comorbidities. Although many therapeutic approaches (anti-obesity, hypoglycemic, lipid lowering drugs, etc.) have been proposed and the treatment of NAFLD is a hot topic of research, there are currently no approved drugs for this indication.

\subsection{Diet}

A low-fat, low-carbohydrate diet with a caloric restriction (500-1000 kcal/day deficit to provoke a weight reduction of $0.5-1.0 \mathrm{~kg} /$ week) is generally recommended. Steatosis may be ameliorated by a $5 \%$ body weight loss, while a $7-10 \%$ is required for improving inflammation and fibrosis [148].

High-fat and high-cholesterol diets have been linked to hepatic steatosis, inflammation, and liver fibrosis [149]. Chronic administration of HFD in rodents has been associated with relatively increased numbers of Firmicutes and decreased numbers of Bacterioidetes species, resulting in a higher F/B ratio [150]. On the other hand, a high-fiber diet has been protective against hepatic inflammation and has been linked to the increased presence of Akkermansia muciniphila [151].

Fructose has been associated with dyslipidemia and insulin resistance. A study comparing fructose and glucose consumption has documented increased visceral adipose tissue volume as well as hepatic de novo lipogenesis, which has been approximately 3 -fold higher in patients with NAFLD [152-154]. Glycotoxin levels, also known as advanced glycation end-products (AGEs), are very high in baked and fried food, especially under high-temperature cooking $[155,156]$. Although there is a scarcity of studies regarding AGEs and NAFLD, an animal study has reported that a high-AGEs diet provoked liver steatosis and fibrosis [157]. On the contrary, caffeine consumption has been demonstrated to be protective against the development of NAFLD as well as the progression of the stage of liver fibrosis [158]. The potential mechanism of the action of caffeine is the decrease in fat accumulation, liver inflammation, and oxidative stress as caffeine may increase glutathione and serve as an ROS scavenger at the cellular level [159]. It is also involved in restoring the $\mathrm{F} / \mathrm{B}$ ratio [160]. In addition, another plausible mechanism of caffeine action is the up-regulation of the expression of Aquaporin-8 in the proximal colon, which is associated with increased growth of the Bifidobacterium species [161]. Moreover, coffee consumption has been shown to correlate with an amelioration of liver enzymes and a decreased risk of cirrhosis and HCC, as well as mortality rates, in a dose-dependent manner [162-164]. Besides, increased coffee intake has been associated with alterations in the gut microbiota composition; in particular, increased levels of Bacteroides, Prevotella, and Porphyromonas have been reported among high consumers of coffee [162-164].

Green tea extract in conjunction with epigallocatechin-3-gallate has been associated with improvements in several obesity parameters, presumably due to the restoration of the F/B ratio and the Bacteroides-to-Prevotella ratio [165-167]. It is noteworthy that patients with NAFLD receiving green tea extract together with $2.5 \%$ caffeine have shown remarkable improvements in liver enzymes after 12 weeks of administration [168]. Another study has confirmed the abovementioned results by reporting improvements in liver enzymes together with a significant decrease in the proportion of body fat in NAFLD patients [169]. In addition, green tea liquid consumption has also been documented to alter the human gut microbiome in many studies [169].

Omega-3 polyunsaturated fatty acids (PUFAs) are suggested to be another promising dietary agent in combating NAFLD. Omega-3 PUFAs regulate the peroxisome proliferator activated receptors (PPARs) and decrease proinflammatory cytokines as well as oxidative stress. In a recent meta-analysis, it has been suggested that omega-3 PUFAs could result in improvements in liver enzymes and the lipid profile [170]. Foods rich in omega-3 PUFAs are found in excess in the Mediterranean diet, which is well known for its beneficial effects in preventing obesity and cardiovascular diseases [170,171]. 


\subsection{Exercise}

Exercise, both aerobic and resistance training, is one of the most promising lifestyle modifications and has been proven to prevent or even reverse NAFLD/NASH [172-174]. As physical inactivity has been associated with the progression of the disease, exercise is suggested to be beneficial not only because of the weight loss but, above and beyond this, also because of the metabolic benefits which accompany exercise training $[175,176]$. In particular, exercise has been implicated in the increased production of several angiogenic factors, thus favoring fatty acid utilization and leading to a decreased entry of FFA into the liver [175-178]. Furthermore, alterations in the composition of the gut microbiota have been reported in response to exercise training. More specifically, in animal models, exercise has been associated with a reduction in the presence of Parabacteroides, Flavobacterium, and Alkaliphilus [179]. Besides, exercise has been related to a relatively increased presence of Verrucomicrobia and a reduction in Proteobacteria in overweight women, as well as a relative reduction in the F/B ratio in patients with T2DM [180]. Alterations that have been associated with exercise also include a reduced presence of the mouse-associated Bacteroidales S24-7 and Rikenellaceae families, which have already been related to increased intrahepatic TG content in mouse models [181]. The significant effect of exercise in NAFLD patients could be partially explained by the interplay between the gut and the liver. For example, exercise has been proven to increase the abundance of SCFAs, mainly butyrate [182]. In addition, exercise exerts a beneficial effect on other gut-derived metabolites related to hepatic metabolism, such as BAs and choline. Furthermore, exercise has been documented to exert epigenetic changes by modulating the expression of various genes implicated in lipid metabolism, such as SREBP-1c, FAT/Cd36, and C/EBPa [175-178]. Exercise provides more beneficial effects than diet alone. Notably, in a study comparing exercise to calorie restriction in HFD-fed animal models, exercise has been shown to increase insulin sensitivity and result in greater LDL reduction, mainly on account of the exercise-induced microbiome alterations [180]. Such modifications in the gut microbiota have been related to improvements in serum LDL cholesterol, liver fat mass, and liver TG [180]. Notably, Barton et al. have documented an increase in the abundance of Akkermansia spp. among athletes with a more active exercise training regimen than among more sedentary individuals, while Allen et al. have reported an increase in the presence of Faecalibacterium spp. with exercise among lean individuals when compared to patients with obesity $[183,184]$. Interestingly, both Akkermansia and Faecalibacterium are known for their beneficial effects on health [185].

\subsection{Bariatric Surgery}

Bariatric surgery is a successful therapy for severe obesity and related metabolic disorders, leading to permanent weight loss and amelioration of metabolic and inflammatory comorbidities such as NAFLD [186,187]. The most widely performed types of bariatric surgery are laparoscopic Roux-en-Y gastric bypass (RYGB) and laparoscopic sleeve gastrectomy (SG). After bariatric surgery, the anatomy, physiology, and energy and substrate metabolism adapt to a new and dynamic status [188,189]. The specific mechanisms through which bariatric surgery affects the composition of the gut microbiota remain to be elucidated. However, several factors have been postulated as being involved in the alteration of the gut microbiota, such as changes in dietary habits, gastrointestinal anatomy, nutrients as well as gastrointestinal transit time and $\mathrm{pH}$, and bile acid metabolism [189]. Studies have documented that after bariatric surgery there is a mild increase in microbial gene richness but not to the levels seen in lean humans [7,190]. There are numerous studies which have investigated the influence of RYGB on the gut microbiota. For example, in a study of 16 patients who underwent RYGB, the gut microbiome was analyzed before and 3 months following surgery. Before surgery, there was relative abundance in the phyla Firmicutes and Actinobacteria, whereas Verrucomicrobia were less abundant when compared to the lean controls. After RYGB, the abundance of these phyla was approximately similar to that in the healthy controls. Only Proteobacteria abundance was more prominent after RYGB and lower in lean subjects [191]. At the genus level, Blautia, Roseburia, Faecalibacterium (Fir- 
micutes), and Bifidobacterium (Actinobacteria) were reduced. It was noteworthy that these genera were still more abundant when compared to lean subjects $[184,185]$. At the species level, Streptococcus spp., Akkermansia muciniphila (Verrucomicrobia), Roseburia feces, Roseburia hominis, and Enterococcus faecalis were in relative abundance, whereas Faecalibacterium prausnitzii was reduced after RYGB [192-199]. Other studies analyzing the composition of the gut microbiota after SG have documented an abundance of the species $C$. comes, D. longicatena, Clostridiales bacterium, Anaerotruncus colihominis, Akkermansia muciniphila, and B. thetaiotaomicron [191-198]. Moreover, the abundance of the species Akkermansia muciniphila, Roseburia spp., Bacteroidetes, and Bifidobacterium have been demonstrated to be increased. One year after SG, the abundance of the phylum Actinobacteria was increased compared to the baseline and three months postoperatively [199]. Overall, several studies have reported substantial alterations in the composition of the gut microbiota after bariatric surgery. Different interventions have resulted in differential microbial profiles, whilst only partial restoration towards the lean gut microbiota composition was noted. Different methods of bariatric surgery, patient characteristics, differences in sample sizes and methodologies as well as the existence of comorbidities, such as T2DM, could account for the abovementioned variable results [192-199].

Bariatric surgery leads to prolonged weight loss with subsequent reductions in hepatic fat mass, inflammation, and fibrosis [186-188]. Indeed, a meta-analysis of 43 studies with 2809 participants has reported a dose-response association with liver inflammation, ballooning, and NAFLD/NASH resolution [186-189]. There is ongoing interest and research on this issue and the results of the ongoing trials are eagerly anticipated.

\subsection{Probiotics}

As gut dysbiosis appears to contribute to the pathogenesis of NAFLD, probiotics have been tested in the prevention and treatment of NAFLD. The term "probiotics" first appeared in 1974 but has since evolved to its current definition as "live microorganisms that confer a health benefit when consumed in adequate amounts," as proposed by the World Health Organization (WHO) in 2002 [200]. To date, probiotics have been shown to improve the lipid profile as well as liver function tests of patients with NAFLD; however, data regarding hepatic histologic alterations are inconclusive. Trials with the administration of probiotics have been confounded by dietary factors which affect intestinal microbiota composition, different formulas, and dosages.

Bifidobacterium and Lactobacillus strains are still the most widely used probiotics in functional foods and dietary supplements, but next-generation probiotics, such as Faecalibacterium prausnitzii, Akkermansia muciniphila, or Clostridia strains, have demonstrated promising results [201]. VSL\#3 and modified VSL\#3 are mixtures of probiotics of the genera Lactobacillus, Bifidobacterium, and Streptococcus or Lactobacillus alone. VSL\#3 has been documented to have a protective effect against NAFLD by inhibiting inflammatory pathways, such as c-Jun N-terminal kinase (JNK) and NF- $\mathrm{B}$, and restoring the number of natural killer (NK) T cells in the liver, caused by high-fat feeding [202,203]. On the contrary, in another animal model study, whilst VSL\#3 did not have any effects on methioninecholine-supplemented diet-induced hepatic steatosis or inflammation, it improved liver fibrosis by down-regulating TGF- $\beta$ signaling [204]. Other studies in rodents have found that probiotics improved the gut microbiota composition by maintaining tight junctions, thus restoring the intestinal mucosal barrier and suppressing the serum LPS levels. Liver inflammatory markers as well as serum cytokines levels were reported to be decreased, in parallel with a reduction in the serum LPS and liver TLR-4 mRNA concentrations [204,205]. In addition, Lactobacillus plantarum NA136 has been shown to reduce the mass of fat tissues in HFD-fed and fructose-fed animal models of NAFLD and to decrease serum liver enzymes. Besides, L. plantarum NA136 reduced lipogenesis and enhanced fatty acid oxidation by stimulating the AMPK pathway to phosphorylate ACC and suppress SREBP-1/FAS signaling in a NASH animal model. Moreover, L. plantarum NA136 reduced oxidative stress in the liver by stimulating the AMPK/NF-E2-related factor 2 (Nrf2) signaling in a NAFLD 
animal model. These results point towards a promising role of L. plantarum NA136 in improving NAFLD [204,205]. Lactobacillus paracasei has been found to reduce the expression of TLR-4, CCL2, and TNF- $\alpha$ and improve liver steatosis. In particular, L. paracasei has been documented to reduce the proportion of M1 Kupffer cells and increase that of M2, leading to an M2-dominant shift in the liver in a NASH animal model, a shift similar to that ascertained in animal models of obesity [204,205]. The addition of a combination of three probiotics has resulted in an enhanced production of lactate concentrations, which in turn led to the activation of lactate-consuming bacteria growth, resulting in a significant enhancement in SCFAs production. Furthermore, the abovementioned combination of probiotics has shown immunomodulatory potential, including enhanced production of anti-inflammatory cytokines, i.e., IL-10 and IL-6, and reduction in the production of proinflammatory chemokines, i.e., IL-8, CXCL 10, and Monocyte Chemoattractant Protein 1 (MCP)-1 [204,205]. However, the data regarding combinations of probiotics are difficult to interpret, as different dosages and proportions of different probiotics are used, while there are other factors to be taken in account, such as the duration of treatment as well as the timing of data collection after the discontinuation of treatment.

An animal study has found that Faecalibacterium prausnitzii may reduce adipose tissue inflammation in rodents and improve the metabolic parameters of liver function [206,207]. Nevertheless, this bacterial species is very oxygen-sensitive and difficult in cultivation and preservation; more research to improve its preservation and viability with the addition of antioxidants, such as riboflavin, cysteine, and cryoprotectant inulin, is ongoing. Another potential probiotic is Akkermansia muciniphila, a mucin-degrading bacterium, which has been found to reduce fat mass and ameliorate dyslipidemia in animal models [208]. Several metaanalyses have also advocated the use of probiotics in NAFLD, documenting improvements in various metabolic and inflammatory parameters. The combined use of Akkermansia muciniphila with metformin has been shown to induce better results than monotherapy alone with regard to serum levels of liver enzymes and sonographic characteristics [208-214].

\subsection{Prebiotics}

Prebiotics constitute non-digestible carbohydrates, which lead to significant changes in the composition or activity of the gut microbiota, resulting in beneficial effects on host health [200]. Most data refer mainly to two chemical substances, inulin-type fructans and galactooligosaccharides. These data have reported increases in the production of Bifidobacteria and Lactobacilli, thus conferring beneficial alterations in the composition and activity of the gut microbiota [200]. Prebiotics may confer benefits to both NAFLD and NASH. In rodents, prebiotics have been documented to induce changes in the composition of the gut microbiota, resulting in increased plasma glucagon-like peptide-2 (GLP-2) levels, thus ameliorating the function of the gut barrier. Furthermore, prebiotics have been demonstrated to decrease liver inflammation and improve metabolic parameters in obesity [210]. Besides, prebiotics, mainly inulin and oligofructose, have been found to better control the growth of Faecalibacterium prausnitzii and Bifidobacterium as well as decrease serum LPS concentrations, due to increased GLP-1 production and the GLP-2-mediated trophic effect on the integrity of the gut barrier. Among patients with obesity, supplementation with oligofructose induced weight loss by regulating appetite hormones such as ghrelin and peptide YY [215].

\subsection{Synbiotics}

Synbiotics are a combination of prebiotics and probiotics, which may be used to replace a dysfunctional gut microbiota [200]. A meta-analysis of probiotics, prebiotics, and synbiotics supplementation in NAFLD has confirmed significant decreases in the body mass index as well as improvements in liver enzymes. Probiotics/synbiotics use has been related to a significant decrease in alanine aminotransferase (ALT) levels and in liver stiffness assessed by elastography [215]. 


\subsection{Antibiotics}

Antibiotics have also been suggested as one of the therapeutic options in NAFLD. Nevertheless, there is conflicting evidence about the efficacy of antimicrobial treatments. The use of norfloxacin and neomycin has been shown to improve liver function in cirrhotic patients by causing changes in bacterial translocation and overgrowth [216]. On the contrary, another study has not shown any beneficial effects on liver function in NAFLD patients administered with norfloxacin. Gangarapu et al. also showed that rifaximin treatment significantly reduced proinflammatory cytokines, ALT, and the NAFLD-liver fat score. This improvement by antibiotics was attributed to alterations in the gut microbiota population and bile acid metabolism as well as to reduced FXR signaling and decreased ceramide levels in the liver [217]. Hence, there is no established role for antibiotics in NAFLD, although longitudinal large-scale studies are lacking. The risk for bacterial drug resistance and potential side effects should also not be overlooked [185].

\subsection{FMT}

FMT has not been very widely used, apart from special circumstances, such as the treatment of severe/recurrent Clostridioides difficile infection, and to a lesser extent in inflammatory bowel disease, metabolic syndrome, and hepatic encephalopathy $[141,218]$. There is a scarcity of studies regarding the use of FMT in NAFLD. Only recently, a study in animal models has documented a beneficial effect on lipid accumulation in the liver as well as liver histology after FMT [219]. Nowadays, FMT has been used successfully in cirrhotic patients with hepatic encephalopathy and severe alcoholic hepatitis $[219,220]$. However, the success rates of FMT are mainly dependent on the "donor" characteristics, in particular fecal microbiota richness, diversity, and compatibility [221-223]. Further studies are needed to assess the long-term efficacy together with the safety of FMT in patients with NAFLD.

Overall, weight loss of $7-10 \%$ of total body weight in patients with biopsy-proven NASH remains the cornerstone of the treatment of NAFLD/NASH. Diet, physical exercise, and bariatric surgery have yielded impressive results, while the use of other conventional measures, such as vitamin E supplementation, the addition of pioglitazone-which may cause weight gain but has been documented to decrease inflammation and liver fibrosis—or glucagon like peptide (GLP) analogs seem to exert hepato-protective properties [8].

\subsection{Bacteriophages}

As most bacteriophages and archaeal viruses are specific to bacterial and archaeal strains, respectively, they may be used to target dysbiotic parts of the microbiota in patients with metabolic disorders in the near future [224]. The therapeutic strategy of targeting a single strain, specifically cytolytisin-positive $E$. faecalis, with the advent of a bacteriophage has only recently been found to be effective in ethanol-induced liver disease experiments using humanized mice [224]. More specifically, patients with alcoholic hepatitis have increased numbers of E. faecalis in their feces. The presence of this cytolytic E. faecalis has been shown to relate to the severity of liver disease as well as mortality among these patients. Using humanized mice that were colonized with bacteria from the feces of patients with alcoholic hepatitis, Duan et al. embarked on investigating the therapeutic effects of bacteriophages that target cytolytic E. faecalis. They have documented that these bacteriophages decrease cytolysin in the liver and mitigate ethanol-induced liver disease in humanized mice. This method with the advent of bacteriophages raises the possibility of modulating the gut microbiota [225-227]. Clinical trials are further required to assess the relevance of the abovementioned findings in humans and to test whether this therapeutic approach is effective for patients with NAFLD/NASH.

\section{Limitations of the Studies}

Although there is a plethora of studies advocating the key role of gut microbiota in maintaining homeostasis and preventing gut dysbiosis and the development of NAFLD via the gut-liver axis, there is significant heterogeneity in terms of basic and clinical research 
on NAFLD/NASH. This heterogeneity could be attributed to the variety and differential degrees in lifestyle modifications, such as diet, the intensity and duration of exercise training, and the administration or not of pro/pre/synbiotics. In addition, there is a paucity of data regarding the role of gut microbiota in NAFLD in humans, and there is no sufficient evidence on the potential role of therapeutics, either in the form of nutritional agents, such as caffeine and polyphenols, or in the form of pro/pre/synbiotics. The reasons behind this scarcity of studies in humans are complicated; NAFLD itself is a complex clinical entity, not always biopsy-proven and with different fibrosis severity, ranging from F0 to F4.

In addition, pro/pre/synbiotics may be administered in different formulas with different concentrations and combinations. Overall, large randomized controlled trials (RCTs) are mandatory with the use of current advances in metagenomics techniques. Multi-omics, although costly and often difficult to perform and interpret, are necessary in studying the role of the gut microbiome in the pathogenesis of NAFLD/NASH [228].

\section{Perspectives and Conclusions}

Nowadays, NAFLD has become a pandemic attributed mainly to Western diet, obesity, and a mostly sedentary lifestyle. Although NAFLD is much more common than in the past, the current methods of diagnosis still have limitations as they are invasive (liver biopsy) or have a low predictive value (noninvasive biomarkers). Human biology should not overlook the gut microbiota, which produce or modulate various chemicals and trigger host reactions, thereby affecting multiple functions, including immunity and metabolism. In this review, we have highlighted the distinct microbiota profile in patients with NAFLD/NASH, which may be correlated to the severity and progression of cirrhosis or HCC. Nevertheless, gut microbiota composition may vary between population groups and different stages of NAFLD, making any conclusive or causative claims about the gut microbiota profile in NAFLD patients challenging. In conclusion, the current limitations of the therapeutic strategies in the fight against NAFLD/NASH should prompt scientists to shed light on newer approaches, with the advent of modern technology, and explore more options regarding the interplay between the gut microbiota, its metabolites, and NAFLD/NASH in terms of diagnosis, prognosis, and therapeutics. It seems likely that modulations in the gut microbiota in patients suffering from liver diseases will be very promising in the near future. Large-scale RCTs in humans are required to evaluate the beneficial properties of probiotics, prebiotics, and synbiotics, their ideal dose, the duration of supplementation, and the durability of their beneficial effects as well as their safety profile in the prevention and treatment of NAFLD.

Author Contributions: Conceptualization, N.V. and M.D.; methodology, N.V., I.K., F.M. and M.D.; writing-original draft preparation, N.V., G.S.C., D.T., D.K. and M.D.; writing-review and editing, N.V., M.D., I.K., T.S., F.M. and D.T.; visualization, G.S.C.; supervision, N.V. and M.D. All authors have read and agreed to the published version of the manuscript.

Funding: This research received no external funding.

Institutional Review Board Statement: Not applicable.

Informed Consent Statement: Not applicable.

Data Availability Statement: Not applicable.

Conflicts of Interest: The authors declare no conflict of interest.

\section{References}

1. Perumpail, B.J.; Khan, M.A.; Yoo, E.R.; Cholankeril, G.; Kim, D.; Ahmed, A. Clinical epidemiology and disease burden of nonalcoholic fatty liver disease. World J. Gastroenterol. 2017, 23, 8263-8276. [CrossRef]

2. Younossi, Z.M.; Koenig, A.B.; Abdelatif, D.; Fazel, Y.; Henry, L.; Wymer, M. Global epidemiology of nonalcoholic fatty liver disease-Meta-analytic assessment of prevalence, incidence, and outcomes. Hepatology 2016, 64, 73-84. [CrossRef] 
3. Williams, C.D.; Stengel, J.; Asike, M.I.; Torres, D.M.; Shaw, J.; Contreras, M.; Landt, C.L.; Harrison, S.A. Prevalence of nonalcoholic fatty liver disease and nonalcoholic steatohepatitis among a largely middle-aged population utilizing ultrasound and liver biopsy: A prospective study. Gastroenterology 2011, 140, 124-131. [CrossRef]

4. Villanueva, A. Hepatocellular Carcinoma. N. Engl. J. Med. 2019, 380, 1450-1462. [CrossRef] [PubMed]

5. Bagaria, S.P.; Ray, P.S.; Sim, M.S.; Ye, X.; Shamonki, J.M.; Cui, X.; Giuliano, A.E. Personalizing breast cancer staging by the inclusion of ER, PR, and HER2. JAMA Surg. 2014, 149, 125-129. [CrossRef] [PubMed]

6. Welzel, T.M.; Graubard, B.I.; Quraishi, S.; Zeuzem, S.; Davila, J.A.; El-Serag, H.B.; McGlynn, K.A. Population-attributable fractions of risk factors for hepatocellular carcinoma in the United States. Am. J. Gastroenterol. 2013, 108, 1314-1321. [CrossRef]

7. Wong, C.R.; Nguyen, M.H.; Lim, J.K. Hepatocellular carcinoma in patients with non-alcoholic fatty liver disease. World J. Gastroenterol. 2016, 22, 8294-8303. [CrossRef] [PubMed]

8. Diehl, A.M.; Day, C. Cause, Pathogenesis, and Treatment of Nonalcoholic Steatohepatitis. N. Engl. J. Med. 2017, 377, $2063-2072$. [CrossRef]

9. Jadhav, K.; Cohen, T.S. Can You Trust Your Gut? Implicating a Disrupted Intestinal Microbiome in the Progression of NAFLD/NASH. Front. Endocrinol. 2020, 11, 592157. [CrossRef]

10. Eslam, M.; George, J. MAFLD: A holistic view to redefining fatty liver disease. J. Hepatol. 2021, 74, 983-985. [CrossRef]

11. Ye, Q.; Zou, B.; Yeo, Y.H.; Li, J.; Huang, D.Q.; Wu, Y.; Yang, H.; Liu, C.; Kam, L.Y.; Tan, X.X.E.; et al. Global prevalence, incidence, and outcomes of non-obese or lean non-alcoholic fatty liver disease: A systematic review and meta-analysis. Lancet Gastroenterol. Hepatol. 2020, 5, 739-752. [CrossRef]

12. Trépo, E.; Nahon, P.; Bontempi, G.; Valenti, L.; Falleti, E.; Nischalke, H.D.; Hamza, S.; Corradini, S.G.; Burza, M.A.; Guyot, E.; et al. Association between the PNPLA3 (rs738409 C $>$ G) variant and hepatocellular carcinoma: Evidence from a meta-analysis of individual participant data. Hepatology 2014, 59, 2170-2177. [CrossRef]

13. Falleti, E.; Fabris, C.; Cmet, S.; Cussigh, A.; Bitetto, D.; Fontanini, E.; Fornasiere, E.; Bignulin, S.; Fumolo, E.; Bignulin, E.; et al. PNPLA3 rs738409C/G polymorphism in cirrhosis: Relationship with the aetiology of liver disease and hepatocellular carcinoma occurrence. Liver Int. 2011, 31, 1137-1143. [CrossRef]

14. Chalasani, N.; Guo, X.; Loomba, R.; Goodarzi, M.O.; Haritunians, T.; Kwon, S.; Cui, J.; Taylor, K.D.; Wilson, L.; Cummings, O.W.; et al. Genome-wide association study identifies variants associated with histologic features of nonalcoholic Fatty liver disease. Gastroenterology 2010, 139, 1567-1576. [CrossRef] [PubMed]

15. Kozlitina, J.; Smagris, E.; Stender, S.; Nordestgaard, B.G.; Zhou, H.H.; Tybjærg-Hansen, A.; Vogt, T.F.; Hobbs, H.H.; Cohen, J.C. Exome-wide association study identifies a TM6SF2 variant that confers susceptibility to nonalcoholic fatty liver disease. Nat. Genet. 2014, 46, 352-356. [CrossRef]

16. Petta, S.; Miele, L.; Bugianesi, E.; Cammà, C.; Rosso, C.; Boccia, S.; Cabibi, D.; Di Marco, V.; Grimaudo, S.; Grieco, A.; et al Glucokinase regulatory protein gene polymorphism affects liver fibrosis in non-alcoholic fatty liver disease. PLoS ONE 2014, 9, e87523. [CrossRef]

17. Mancina, R.M.; Dongiovanni, P.; Petta, S.; Pingitore, P.; Meroni, M.; Rametta, R.; Borén, J.; Montalcini, T.; Pujia, A.; Wiklund, O.; et al. The MBOAT7-TMC4 Variant rs641738 Increases Risk of Nonalcoholic Fatty Liver Disease in Individuals of European Descent. Gastroenterology 2016, 150, 1219-1230.e1216. [CrossRef] [PubMed]

18. Lau, L.H.S.; Wong, S.H. Microbiota, Obesity and NAFLD. Adv. Exp. Med. Biol. 2018, 1061, 111-125. [CrossRef]

19. Abdelmalek, M.F.; Liu, C.; Shuster, J.; Nelson, D.R.; Asal, N.R. Familial aggregation of insulin resistance in first-degree relatives of patients with nonalcoholic fatty liver disease. Clin. Gastroenterol. Hepatol. 2006, 4, 1162-1169. [CrossRef]

20. Loomba, R.; Hwang, S.J.; O’Donnell, C.J.; Ellison, R.C.; Vasan, R.S.; D’Agostino, R.B., Sr.; Liang, T.J.; Fox, C.S. Parental obesity and offspring serum alanine and aspartate aminotransferase levels: The Framingham heart study. Gastroenterology 2008, 134, 953-959. [CrossRef] [PubMed]

21. Vilar, L.; Oliveira, C.P.; Faintuch, J.; Mello, E.S.; Nogueira, M.A.; Santos, T.E.; Alves, V.A.; Carrilho, F.J. High-fat diet: A trigger of non-alcoholic steatohepatitis? Preliminary findings in obese subjects. Nutrition 2008, 24, 1097-1102. [CrossRef] [PubMed]

22. Abdelmalek, M.F.; Suzuki, A.; Guy, C.; Unalp-Arida, A.; Colvin, R.; Johnson, R.J.; Diehl, A.M. Increased fructose consumption is associated with fibrosis severity in patients with nonalcoholic fatty liver disease. Hepatology 2010, 51, 1961-1971. [CrossRef]

23. Zelber-Sagi, S.; Nitzan-Kaluski, D.; Goldsmith, R.; Webb, M.; Blendis, L.; Halpern, Z.; Oren, R. Long term nutritional intake and the risk for non-alcoholic fatty liver disease (NAFLD): A population based study. J. Hepatol. 2007, 47, 711-717. [CrossRef]

24. Ouyang, X.; Cirillo, P.; Sautin, Y.; McCall, S.; Bruchette, J.L.; Diehl, A.M.; Johnson, R.J.; Abdelmalek, M.F. Fructose consumption as a risk factor for non-alcoholic fatty liver disease. J. Hepatol. 2008, 48, 993-999. [CrossRef]

25. Araya, J.; Rodrigo, R.; Videla, L.A.; Thielemann, L.; Orellana, M.; Pettinelli, P.; Poniachik, J. Increase in long-chain polyunsaturated fatty acid n-6/n-3 ratio in relation to hepatic steatosis in patients with non-alcoholic fatty liver disease. Clin. Sci. 2004, 106, 635-643. [CrossRef] [PubMed]

26. Cortez-Pinto, H.; Jesus, L.; Barros, H.; Lopes, C.; Moura, M.C.; Camilo, M.E. How different is the dietary pattern in non-alcoholic steatohepatitis patients? Clin. Nutr. 2006, 25, 816-823. [CrossRef] [PubMed]

27. Vallianou, N.; Liu, J.; Dalamaga, M. What are the key points in the association between the gut microbiome and nonalcoholic fatty liver disease? Metabol. Open 2019, 1, 9-10. [CrossRef] 
28. Vallianou, N.; Stratigou, T.; Christodoulatos, G.S.; Dalamaga, M. Understanding the Role of the Gut Microbiome and Microbial Metabolites in Obesity and Obesity-Associated Metabolic Disorders: Current Evidence and Perspectives. Curr. Obes. Rep. 2019, 8, 317-332. [CrossRef]

29. Hoozemans, J.; de Brauw, M.; Nieuwdorp, M.; Gerdes, V. Gut Microbiome and Metabolites in Patients with NAFLD and after Bariatric Surgery: A Comprehensive Review. Metabolites 2021, 11, 353. [CrossRef]

30. Donnelly, K.L.; Smith, C.I.; Schwarzenberg, S.J.; Jessurun, J.; Boldt, M.D.; Parks, E.J. Sources of fatty acids stored in liver and secreted via lipoproteins in patients with nonalcoholic fatty liver disease. J. Clin. Investig. 2005, 115, 1343-1351. [CrossRef]

31. Arab, J.P.; Karpen, S.J.; Dawson, P.A.; Arrese, M.; Trauner, M. Bile acids and nonalcoholic fatty liver disease: Molecular insights and therapeutic perspectives. Hepatology 2017, 65, 350-362. [CrossRef]

32. Jiang, W.; Wu, N.; Wang, X.; Chi, Y.; Zhang, Y.; Qiu, X.; Hu, Y.; Li, J.; Liu, Y. Dysbiosis gut microbiota associated with inflammation and impaired mucosal immune function in intestine of humans with non-alcoholic fatty liver disease. Sci. Rep. 2015, 5, 8096. [CrossRef]

33. Zhu, L.; Baker, S.S.; Gill, C.; Liu, W.; Alkhouri, R.; Baker, R.D.; Gill, S.R. Characterization of gut microbiomes in nonalcoholic steatohepatitis (NASH) patients: A connection between endogenous alcohol and NASH. Hepatology 2013, 57, 601-609. [CrossRef] [PubMed]

34. Gerbes, A.; Zoulim, F.; Tilg, H.; Dufour, J.F.; Bruix, J.; Paradis, V.; Salem, R.; Peck-Radosavljevic, M.; Galle, P.R.; Greten, T.F.; et al. Gut roundtable meeting paper: Selected recent advances in hepatocellular carcinoma. Gut 2018, 67, 380-388. [CrossRef]

35. Satapathy, S.K.; Banerjee, P.; Pierre, J.F.; Higgins, D.; Dutta, S.; Heda, R.; Khan, S.D.; Mupparaju, V.K.; Mas, V.; Nair, S.; et al. Characterization of Gut Microbiome in Liver Transplant Recipients with Nonalcoholic Steatohepatitis. Transplant. Direct 2020, 6, e625. [CrossRef] [PubMed]

36. Del Chierico, F.; Nobili, V.; Vernocchi, P.; Russo, A.; De Stefanis, C.; Gnani, D.; Furlanello, C.; Zandonà, A.; Paci, P.; Capuani, G.; et al. Gut microbiota profiling of pediatric nonalcoholic fatty liver disease and obese patients unveiled by an integrated meta-omics-based approach. Hepatology 2017, 65, 451-464. [CrossRef] [PubMed]

37. Nair, S.; Cope, K.; Risby, T.H.; Diehl, A.M. Obesity and female gender increase breath ethanol concentration: Potential implications for the pathogenesis of nonalcoholic steatohepatitis. Am. J. Gastroenterol. 2001, 96, 1200-1204. [CrossRef]

38. Rao, R.K.; Seth, A.; Sheth, P. Recent Advances in Alcoholic Liver Disease I. Role of intestinal permeability and endotoxemia in alcoholic liver disease. Am. J. Physiol. Gastrointest. Liver Physiol. 2004, 286, G881-G884. [CrossRef]

39. Xu, J.; Lai, K.K.Y.; Verlinsky, A.; Lugea, A.; French, S.W.; Cooper, M.P.; Ji, C.; Tsukamoto, H. Synergistic steatohepatitis by moderate obesity and alcohol in mice despite increased adiponectin and p-AMPK. J. Hepatol. 2011, 55, 673-682. [CrossRef] [PubMed]

40. de Medeiros, I.C.; de Lima, J.G. Is nonalcoholic fatty liver disease an endogenous alcoholic fatty liver disease?-A mechanistic hypothesis. Med. Hypotheses 2015, 85, 148-152. [CrossRef]

41. Schwenger, K.J.; Clermont-Dejean, N.; Allard, J.P. The role of the gut microbiome in chronic liver disease: The clinical evidence revised. JHEP Rep. 2019, 1, 214-226. [CrossRef] [PubMed]

42. Le Roy, T.; Llopis, M.; Lepage, P.; Bruneau, A.; Rabot, S.; Bevilacqua, C.; Martin, P.; Philippe, C.; Walker, F.; Bado, A.; et al. Intestinal microbiota determines development of non-alcoholic fatty liver disease in mice. Gut 2013, 62, 1787-1794. [CrossRef] [PubMed]

43. Yuan, J.; Chen, C.; Cui, J.; Lu, J.; Yan, C.; Wei, X.; Zhao, X.; Li, N.; Li, S.; Xue, G.; et al. Fatty Liver Disease Caused by High-Alcohol-Producing Klebsiella pneumoniae. Cell Metab. 2019, 30, 675-688.e677. [CrossRef]

44. Rahman, K.; Desai, C.; Iyer, S.S.; Thorn, N.E.; Kumar, P.; Liu, Y.; Smith, T.; Neish, A.S.; Li, H.; Tan, S.; et al. Loss of Junctional Adhesion Molecule a Promotes Severe Steatohepatitis in Mice on a Diet High in Saturated Fat, Fructose, and Cholesterol. Gastroenterology 2016, 151, 733-746.e712. [CrossRef]

45. Pierantonelli, I.; Rychlicki, C.; Agostinelli, L.; Giordano, D.M.; Gaggini, M.; Fraumene, C.; Saponaro, C.; Manghina, V.; Sartini, L.; Mingarelli, E.; et al. Lack of NLRP3-inflammasome leads to gut-liver axis derangement, gut dysbiosis and a worsened phenotype in a mouse model of NAFLD. Sci. Rep. 2017, 7, 12200. [CrossRef]

46. Llorente, C.; Jepsen, P.; Inamine, T.; Wang, L.; Bluemel, S.; Wang, H.J.; Loomba, R.; Bajaj, J.S.; Schubert, M.L.; Sikaroodi, M.; et al. Gastric acid suppression promotes alcoholic liver disease by inducing overgrowth of intestinal Enterococcus. Nat. Commun. 2017, 8, 837. [CrossRef]

47. Gart, E.; Souto Lima, E.; Schuren, F.; de Ruiter, C.G.F.; Attema, J.; Verschuren, L.; Keijer, J.; Salic, K.; Morrison, M.C.; Kleemann, R. Diet-Independent Correlations between Bacteria and Dysfunction of Gut, Adipose Tissue, and Liver: A Comprehensive Microbiota Analysis in Feces and Mucosa of the Ileum and Colon in Obese Mice with NAFLD. Int. J. Mol. Sci. $2018,20,1$. [CrossRef]

48. Schneider, K.M.; Mohs, A.; Kilic, K.; Candels, L.S.; Elfers, C.; Bennek, E.; Schneider, L.B.; Heymann, F.; Gassler, N.; Penders, J.; et al. Intestinal Microbiota Protects against MCD Diet-Induced Steatohepatitis. Int. J. Mol. Sci. 2019, 20, 308. [CrossRef]

49. Petrov, P.D.; García-Mediavilla, M.V.; Guzmán, C.; Porras, D.; Nistal, E.; Martínez-Flórez, S.; Castell, J.V.; González-Gallego, J.; Sánchez-Campos, S.; Jover, R. A Network Involving Gut Microbiota, Circulating Bile Acids, and Hepatic Metabolism Genes That Protects Against Non-Alcoholic Fatty Liver Disease. Mol. Nutr. Food Res. 2019, 63, e1900487. [CrossRef] [PubMed] 
50. Chen, M.; Hui, S.; Lang, H.; Zhou, M.; Zhang, Y.; Kang, C.; Zeng, X.; Zhang, Q.; Yi, L.; Mi, M. SIRT3 Deficiency Promotes High-Fat Diet-Induced Nonalcoholic Fatty Liver Disease in Correlation with Impaired Intestinal Permeability through Gut Microbial Dysbiosis. Mol. Nutr. Food Res. 2019, 63, e1800612. [CrossRef]

51. de Sant'Ana, L.P.; Ribeiro, D.J.S.; Martins, A.M.A.; Dos Santos, F.N.; Corrêa, R.; Almeida, R.D.N.; Eberlin, M.N.; Maurice, C.F.; Magalhães, K.G. Absence of the Caspases 1/11 Modulates Liver Global Lipid Profile and Gut Microbiota in High-Fat-Diet-Induced Obese Mice. Front. Immunol. 2019, 10, 2926. [CrossRef]

52. Ahmad, M.I.; Ijaz, M.U.; Hussain, M.; Haq, I.U.; Zhao, D.; Li, C. High-Fat Proteins Drive Dynamic Changes in Gut Microbiota, Hepatic Metabolome, and Endotoxemia-TLR-4-NFkB-Mediated Inflammation in Mice. J. Agric. Food Chem. 2020, 68, 11710-11725. [CrossRef]

53. Cavallari, J.F.; Pokrajac, N.T.; Zlitni, S.; Foley, K.P.; Henriksbo, B.D.; Schertzer, J.D. NOD2 in hepatocytes engages a liver-gut axis to protect against steatosis, fibrosis, and gut dysbiosis during fatty liver disease in mice. Am. J. Physiol. Endocrinol. Metab. 2020, 319, E305-E314. [CrossRef] [PubMed]

54. Zhang, X.; Coker, O.O.; Chu, E.S.; Fu, K.; Lau, H.C.H.; Wang, Y.X.; Chan, A.W.H.; Wei, H.; Yang, X.; Sung, J.J.Y.; et al. Dietary cholesterol drives fatty liver-associated liver cancer by modulating gut microbiota and metabolites. Gut 2021, 70, 761-774. [CrossRef]

55. Belgaumkar, A.P.; Vincent, R.P.; Carswell, K.A.; Hughes, R.D.; Alaghband-Zadeh, J.; Mitry, R.R.; le Roux, C.W.; Patel, A.G. Changes in Bile Acid Profile After Laparoscopic Sleeve Gastrectomy are Associated with Improvements in Metabolic Profile and Fatty Liver Disease. Obes. Surg. 2016, 26, 1195-1202. [CrossRef] [PubMed]

56. Boursier, J.; Mueller, O.; Barret, M.; Machado, M.; Fizanne, L.; Araujo-Perez, F.; Guy, C.D.; Seed, P.C.; Rawls, J.F.; David, L.A.; et al. The severity of nonalcoholic fatty liver disease is associated with gut dysbiosis and shift in the metabolic function of the gut microbiota. Hepatology 2016, 63, 764-775. [CrossRef]

57. Loomba, R.; Seguritan, V.; Li, W.; Long, T.; Klitgord, N.; Bhatt, A.; Dulai, P.S.; Caussy, C.; Bettencourt, R.; Highlander, S.K.; et al. Gut Microbiome-Based Metagenomic Signature for Non-invasive Detection of Advanced Fibrosis in Human Nonalcoholic Fatty Liver Disease. Cell Metab. 2017, 25, 1054-1062.e1055. [CrossRef]

58. Puri, P.; Daita, K.; Joyce, A.; Mirshahi, F.; Santhekadur, P.K.; Cazanave, S.; Luketic, V.A.; Siddiqui, M.S.; Boyett, S.; Min, H.K.; et al. The presence and severity of nonalcoholic steatohepatitis is associated with specific changes in circulating bile acids. Hepatology 2018, 67, 534-548. [CrossRef]

59. Hoyles, L.; Fernández-Real, J.M.; Federici, M.; Serino, M.; Abbott, J.; Charpentier, J.; Heymes, C.; Luque, J.L.; Anthony, E.; Barton, R.H.; et al. Molecular phenomics and metagenomics of hepatic steatosis in non-diabetic obese women. Nat. Med. 2018, 24, 1070-1080. [CrossRef] [PubMed]

60. Caussy, C.; Hsu, C.; Lo, M.T.; Liu, A.; Bettencourt, R.; Ajmera, V.H.; Bassirian, S.; Hooker, J.; Sy, E.; Richards, L.; et al. Link between gut-microbiome derived metabolite and shared gene-effects with hepatic steatosis and fibrosis in NAFLD. Hepatology 2018, 68, 918-932. [CrossRef]

61. Caussy, C.; Tripathi, A.; Humphrey, G.; Bassirian, S.; Singh, S.; Faulkner, C.; Bettencourt, R.; Rizo, E.; Richards, L.; Xu, Z.Z.; et al. A gut microbiome signature for cirrhosis due to nonalcoholic fatty liver disease. Nat. Commun. 2019, 10, 1406. [CrossRef]

62. Lee, G.; You, H.J.; Bajaj, J.S.; Joo, S.K.; Yu, J.; Park, S.; Kang, H.; Park, J.H.; Kim, J.H.; Lee, D.H.; et al. Distinct signatures of gut microbiome and metabolites associated with significant fibrosis in non-obese NAFLD. Nat. Commun. 2020, 11, 4982. [CrossRef]

63. Adams, L.A.; Wang, Z.; Liddle, C.; Melton, P.E.; Ariff, A.; Chandraratna, H.; Tan, J.; Ching, H.; Coulter, S.; de Boer, B.; et al. Bile acids associate with specific gut microbiota, low-level alcohol consumption and liver fibrosis in patients with non-alcoholic fatty liver disease. Liver Int. 2020, 40, 1356-1365. [CrossRef]

64. Masarone, M.; Troisi, J.; Aglitti, A.; Torre, P.; Colucci, A.; Dallio, M.; Federico, A.; Balsano, C.; Persico, M. Untargeted metabolomics as a diagnostic tool in NAFLD: Discrimination of steatosis, steatohepatitis and cirrhosis. Metabolomics 2021, 17, 12. [CrossRef]

65. Nimer, N.; Choucair, I.; Wang, Z.; Nemet, I.; Li, L.; Gukasyan, J.; Weeks, T.L.; Alkhouri, N.; Zein, N.; Tang, W.H.W.; et al. Bile acids profile, histopathological indices and genetic variants for non-alcoholic fatty liver disease progression. Metabolism 2021, 116, 154457. [CrossRef]

66. Wolever, T.M.; Brighenti, F.; Royall, D.; Jenkins, A.L.; Jenkins, D.J. Effect of rectal infusion of short chain fatty acids in human subjects. Am. J. Gastroenterol. 1989, 84, 1027-1033. [PubMed]

67. McNeil, N.I. The contribution of the large intestine to energy supplies in man. Am. J. Clin. Nutr. 1984, 39, 338-342. [CrossRef]

68. Gao, Z.; Yin, J.; Zhang, J.; Ward, R.E.; Martin, R.J.; Lefevre, M.; Cefalu, W.T.; Ye, J. Butyrate improves insulin sensitivity and increases energy expenditure in mice. Diabetes 2009, 58, 1509-1517. [CrossRef] [PubMed]

69. den Besten, G.; Bleeker, A.; Gerding, A.; van Eunen, K.; Havinga, R.; van Dijk, T.H.; Oosterveer, M.H.; Jonker, J.W.; Groen, A.K.; Reijngoud, D.J.; et al. Short-Chain Fatty Acids Protect Against High-Fat Diet-Induced Obesity via a PPAR $\gamma$-Dependent Switch From Lipogenesis to Fat Oxidation. Diabetes 2015, 64, 2398-2408. [CrossRef] [PubMed]

70. Singh, R.; Kaushik, S.; Wang, Y.; Xiang, Y.; Novak, I.; Komatsu, M.; Tanaka, K.; Cuervo, A.M.; Czaja, M.J. Autophagy regulates lipid metabolism. Nature 2009, 458, 1131-1135. [CrossRef] [PubMed]

71. Sinha, R.A.; You, S.H.; Zhou, J.; Siddique, M.M.; Bay, B.H.; Zhu, X.; Privalsky, M.L.; Cheng, S.Y.; Stevens, R.D.; Summers, S.A.; et al. Thyroid hormone stimulates hepatic lipid catabolism via activation of autophagy. J. Clin. Investig. 2012, 122, 2428-2438. [CrossRef] 
72. Samuel, B.S.; Shaito, A.; Motoike, T.; Rey, F.E.; Backhed, F.; Manchester, J.K.; Hammer, R.E.; Williams, S.C.; Crowley, J.; Yanagisawa, M.; et al. Effects of the gut microbiota on host adiposity are modulated by the short-chain fatty-acid binding $\mathrm{G}$ protein-coupled receptor, Gpr41. Proc. Natl. Acad. Sci. USA 2008, 105, 16767-16772. [CrossRef]

73. Musso, G.; Gambino, R.; Cassader, M. Obesity, diabetes, and gut microbiota: The hygiene hypothesis expanded? Diabetes Care 2010, 33, 2277-2284. [CrossRef] [PubMed]

74. Svegliati-Baroni, G.; Saccomanno, S.; Rychlicki, C.; Agostinelli, L.; De Minicis, S.; Candelaresi, C.; Faraci, G.; Pacetti, D.; Vivarelli, M.; Nicolini, D.; et al. Glucagon-like peptide-1 receptor activation stimulates hepatic lipid oxidation and restores hepatic signalling alteration induced by a high-fat diet in nonalcoholic steatohepatitis. Liver Int. 2011, 31, 1285-1297. [CrossRef]

75. Tolhurst, G.; Heffron, H.; Lam, Y.S.; Parker, H.E.; Habib, A.M.; Diakogiannaki, E.; Cameron, J.; Grosse, J.; Reimann, F.; Gribble, F.M. Short-chain fatty acids stimulate glucagon-like peptide-1 secretion via the G-protein-coupled receptor FFAR2. Diabetes 2012, 61, 364-371. [CrossRef] [PubMed]

76. Ge, H.; Li, X.; Weiszmann, J.; Wang, P.; Baribault, H.; Chen, J.L.; Tian, H.; Li, Y. Activation of G protein-coupled receptor 43 in adipocytes leads to inhibition of lipolysis and suppression of plasma free fatty acids. Endocrinology 2008, 149, 4519-4526. [CrossRef] [PubMed]

77. Zhao, S.; Jang, C.; Liu, J.; Uehara, K.; Gilbert, M.; Izzo, L.; Zeng, X.; Trefely, S.; Fernandez, S.; Carrer, A.; et al. Dietary fructose feeds hepatic lipogenesis via microbiota-derived acetate. Nature 2020, 579, 586-591. [CrossRef] [PubMed]

78. Iannucci, L.F.; Sun, J.; Singh, B.K.; Zhou, J.; Kaddai, V.A.; Lanni, A.; Yen, P.M.; Sinha, R.A. Short chain fatty acids induce UCP2-mediated autophagy in hepatic cells. Biochem. Biophys. Res. Commun. 2016, 480, 461-467. [CrossRef]

79. den Besten, G.; Lange, K.; Havinga, R.; van Dijk, T.H.; Gerding, A.; van Eunen, K.; Müller, M.; Groen, A.K.; Hooiveld, G.J.; Bakker, B.M.; et al. Gut-derived short-chain fatty acids are vividly assimilated into host carbohydrates and lipids. Am. J. Physiol. Gastrointest. Liver Physiol. 2013, 305, G900-G910. [CrossRef] [PubMed]

80. Waldecker, M.; Kautenburger, T.; Daumann, H.; Busch, C.; Schrenk, D. Inhibition of histone-deacetylase activity by short-chain fatty acids and some polyphenol metabolites formed in the colon. J. Nutr. Biochem. 2008, 19, 587-593. [CrossRef]

81. Juanola, O.; Ferrusquía-Acosta, J.; García-Villalba, R.; Zapater, P.; Magaz, M.; Marín, A.; Olivas, P.; Baiges, A.; Bellot, P.; Turon, F.; et al. Circulating levels of butyrate are inversely related to portal hypertension, endotoxemia, and systemic inflammation in patients with cirrhosis. FASEB J. 2019, 33, 11595-11605. [CrossRef] [PubMed]

82. Zhai, S.; Qin, S.; Li, L.; Zhu, L.; Zou, Z.; Wang, L. Dietary butyrate suppresses inflammation through modulating gut microbiota in high-fat diet-fed mice. FEMS Microbiol. Lett. 2019, 366, fnz153. [CrossRef]

83. Tilg, H.; Moschen, A.R.; Szabo, G. Interleukin-1 and inflammasomes in alcoholic liver disease/acute alcoholic hepatitis and nonalcoholic fatty liver disease/nonalcoholic steatohepatitis. Hepatology 2016, 64, 955-965. [CrossRef] [PubMed]

84. Rivera, C.A.; Adegboyega, P.; van Rooijen, N.; Tagalicud, A.; Allman, M.; Wallace, M. Toll-like receptor-4 signaling and Kupffer cells play pivotal roles in the pathogenesis of non-alcoholic steatohepatitis. J. Hepatol. 2007, 47, 571-579. [CrossRef] [PubMed]

85. Harte, A.L.; da Silva, N.F.; Creely, S.J.; McGee, K.C.; Billyard, T.; Youssef-Elabd, E.M.; Tripathi, G.; Ashour, E.; Abdalla, M.S.; Sharada, H.M.; et al. Elevated endotoxin levels in non-alcoholic fatty liver disease. J. Inflamm. 2010, 7, 15. [CrossRef] [PubMed]

86. Mehta, N.N.; McGillicuddy, F.C.; Anderson, P.D.; Hinkle, C.C.; Shah, R.; Pruscino, L.; Tabita-Martinez, J.; Sellers, K.F.; Rickels, M.R.; Reilly, M.P. Experimental endotoxemia induces adipose inflammation and insulin resistance in humans. Diabetes 2010, 59, 172-181. [CrossRef]

87. Wu, R.; Nakatsu, G.; Zhang, X.; Yu, J. Pathophysiological mechanisms and therapeutic potentials of macrophages in non-alcoholic steatohepatitis. Expert Opin. Ther. Targets 2016, 20, 615-626. [CrossRef]

88. Schroder, K.; Tschopp, J. The inflammasomes. Cell 2010, 140, 821-832. [CrossRef]

89. Stienstra, R.; van Diepen, J.A.; Tack, C.J.; Zaki, M.H.; van de Veerdonk, F.L.; Perera, D.; Neale, G.A.; Hooiveld, G.J.; Hijmans, A.; Vroegrijk, I.; et al. Inflammasome is a central player in the induction of obesity and insulin resistance. Proc. Natl. Acad. Sci. USA 2011, 108, 15324-15329. [CrossRef]

90. Henao-Mejia, J.; Elinav, E.; Jin, C.; Hao, L.; Mehal, W.Z.; Strowig, T.; Thaiss, C.A.; Kau, A.L.; Eisenbarth, S.C.; Jurczak, M.J.; et al. Inflammasome-mediated dysbiosis regulates progression of NAFLD and obesity. Nature 2012, 482, 179-185. [CrossRef]

91. Yang, G.; Lee, H.E.; Lee, J.Y. A pharmacological inhibitor of NLRP3 inflammasome prevents non-alcoholic fatty liver disease in a mouse model induced by high fat diet. Sci. Rep. 2016, 6, 24399. [CrossRef]

92. Csak, T.; Velayudham, A.; Hritz, I.; Petrasek, J.; Levin, I.; Lippai, D.; Catalano, D.; Mandrekar, P.; Dolganiuc, A.; Kurt-Jones, E.; et al. Deficiency in myeloid differentiation factor-2 and toll-like receptor 4 expression attenuates nonalcoholic steatohepatitis and fibrosis in mice. Am. J. Physiol. Gastrointest. Liver Physiol. 2011, 300, G433-G441. [CrossRef]

93. Garcia-Martinez, I.; Santoro, N.; Chen, Y.; Hoque, R.; Ouyang, X.; Caprio, S.; Shlomchik, M.J.; Coffman, R.L.; Candia, A.; Mehal, W.Z. Hepatocyte mitochondrial DNA drives nonalcoholic steatohepatitis by activation of TLR9. J. Clin. Investig. 2016, 126, 859-864. [CrossRef]

94. Singh, V.; Chassaing, B.; Zhang, L.; San Yeoh, B.; Xiao, X.; Kumar, M.; Baker, M.T.; Cai, J.; Walker, R.; Borkowski, K.; et al. Microbiota-Dependent Hepatic Lipogenesis Mediated by Stearoyl CoA Desaturase 1 (SCD1) Promotes Metabolic Syndrome in TLR5-Deficient Mice. Cell Metab. 2015, 22, 983-996. [CrossRef]

95. Moran-Ramos, S.; López-Contreras, B.E.; Canizales-Quinteros, S. Gut Microbiota in Obesity and Metabolic Abnormalities: A Matter of Composition or Functionality? Arch. Med. Res. 2017, 48, 735-753. [CrossRef]

96. Yuan, L.; Bambha, K. Bile acid receptors and nonalcoholic fatty liver disease. World J. Hepatol. 2015, 7, 2811-2818. [CrossRef] 
97. Dawson, P.A.; Karpen, S.J. Intestinal transport and metabolism of bile acids. J. Lipid Res. 2015, 56, 1085-1099. [CrossRef]

98. Ferslew, B.C.; Xie, G.; Johnston, C.K.; Su, M.; Stewart, P.W.; Jia, W.; Brouwer, K.L.; Barritt, A.S.t. Altered Bile Acid Metabolome in Patients with Nonalcoholic Steatohepatitis. Dig. Dis. Sci. 2015, 60, 3318-3328. [CrossRef]

99. Appleby, R.N.; Moghul, I.; Khan, S.; Yee, M.; Manousou, P.; Neal, T.D.; Walters, J.R.F. Non-alcoholic fatty liver disease is associated with dysregulated bile acid synthesis and diarrhea: A prospective observational study. PLoS ONE 2019, 14, e0211348. [CrossRef]

100. Yara, S.-I.; Ikegami, T.; Miyazaki, T.; Murakami, M.; Iwamoto, J.; Hirayama, T.; Kohjima, M.; Nakamuta, M.; Honda, A. Circulating bile acid profiles in Japanese patients with NASH. GastroHep 2019, 1, 302-310. [CrossRef]

101. Chen, J.; Zheng, M.; Liu, J.; Luo, Y.; Yang, W.; Yang, J.; Liu, J.; Zhou, J.; Xu, C.; Zhao, F.; et al. Ratio of Conjugated Chenodeoxycholic to Muricholic Acids is Associated with Severity of Nonalcoholic Steatohepatitis. Obesity 2019, 27, 2055-2066. [CrossRef]

102. Pols, T.W.; Noriega, L.G.; Nomura, M.; Auwerx, J.; Schoonjans, K. The bile acid membrane receptor TGR5: A valuable metabolic target. Dig. Dis. 2011, 29, 37-44. [CrossRef]

103. Fiorucci, S.; Biagioli, M.; Zampella, A.; Distrutti, E. Bile Acids Activated Receptors Regulate Innate Immunity. Front. Immunol. 2018, 9, 1853. [CrossRef]

104. Thomas, C.; Gioiello, A.; Noriega, L.; Strehle, A.; Oury, J.; Rizzo, G.; Macchiarulo, A.; Yamamoto, H.; Mataki, C.; Pruzanski, M.; et al. TGR5-mediated bile acid sensing controls glucose homeostasis. Cell Metab. 2009, 10, 167-177. [CrossRef]

105. Keitel, V.; Donner, M.; Winandy, S.; Kubitz, R.; Häussinger, D. Expression and function of the bile acid receptor TGR5 in Kupffer cells. Biochem. Biophys. Res. Commun. 2008, 372, 78-84. [CrossRef]

106. Molinaro, A.; Wahlström, A.; Marschall, H.U. Role of Bile Acids in Metabolic Control. Trends Endocrinol. Metab. 2018, 29 , 31-41. [CrossRef]

107. Wang, Z.; Klipfell, E.; Bennett, B.J.; Koeth, R.; Levison, B.S.; Dugar, B.; Feldstein, A.E.; Britt, E.B.; Fu, X.; Chung, Y.M.; et al. Gut flora metabolism of phosphatidylcholine promotes cardiovascular disease. Nature 2011, 472, 57-63. [CrossRef]

108. Mehedint, M.G.; Zeisel, S.H. Choline's role in maintaining liver function: New evidence for epigenetic mechanisms. Curr. Opin. Clin. Nutr. Metab. Care 2013, 16, 339-345. [CrossRef]

109. Yao, Z.M.; Vance, D.E. Reduction in VLDL, but not HDL, in plasma of rats deficient in choline. Biochem. Cell Biol. 1990, 68, 552-558. [CrossRef]

110. Stephenson, K.; Kennedy, L.; Hargrove, L.; Demieville, J.; Thomson, J.; Alpini, G.; Francis, H. Updates on Dietary Models of Nonalcoholic Fatty Liver Disease: Current Studies and Insights. Gene Expr. 2018, 18, 5-17. [CrossRef]

111. Dumas, M.E.; Barton, R.H.; Toye, A.; Cloarec, O.; Blancher, C.; Rothwell, A.; Fearnside, J.; Tatoud, R.; Blanc, V.; Lindon, J.C.; et al. Metabolic profiling reveals a contribution of gut microbiota to fatty liver phenotype in insulin-resistant mice. Proc. Natl. Acad. Sci. USA 2006, 103, 12511-12516. [CrossRef]

112. Tang, W.H.; Hazen, S.L. Microbiome, trimethylamine N-oxide, and cardiometabolic disease. Transl. Res. 2017, $179,108-115$. [CrossRef]

113. Chen, Y.M.; Liu, Y.; Zhou, R.F.; Chen, X.L.; Wang, C.; Tan, X.Y.; Wang, L.J.; Zheng, R.D.; Zhang, H.W.; Ling, W.H.; et al. Associations of gut-flora-dependent metabolite trimethylamine-N-oxide, betaine and choline with non-alcoholic fatty liver disease in adults. Sci. Rep. 2016, 6, 19076. [CrossRef]

114. León-Mimila, P.; Villamil-Ramírez, H.; Li, X.S.; Shih, D.M.; Hui, S.T.; Ocampo-Medina, E.; López-Contreras, B.; Morán-Ramos, S.; Olivares-Arevalo, M.; Grandini-Rosales, P.; et al. Trimethylamine N-oxide levels are associated with NASH in obese subjects with type 2 diabetes. Diabetes Metab. 2021, 47, 101183. [CrossRef]

115. Barrea, L.; Annunziata, G.; Muscogiuri, G.; Di Somma, C.; Laudisio, D.; Maisto, M.; de Alteriis, G.; Tenore, G.C.; Colao, A.; Savastano, S. Trimethylamine-N-oxide (TMAO) as Novel Potential Biomarker of Early Predictors of Metabolic Syndrome. Nutrients 2018, 10, 1971. [CrossRef]

116. De Chiara, F.; Thomsen, K.L.; Habtesion, A.; Jones, H.; Davies, N.; Gracia-Sancho, J.; Manicardi, N.; Hall, A.; Andreola, F.; Paish, H.L.; et al. Ammonia Scavenging Prevents Progression of Fibrosis in Experimental Nonalcoholic Fatty Liver Disease. Hepatology 2020, 71, 874-892. [CrossRef]

117. De Chiara, F.; Heebøll, S.; Marrone, G.; Montoliu, C.; Hamilton-Dutoit, S.; Ferrandez, A.; Andreola, F.; Rombouts, K.; Grønbæk, H.; Felipo, V.; et al. Urea cycle dysregulation in non-alcoholic fatty liver disease. J. Hepatol. 2018, 69, 905-915. [CrossRef]

118. Thomsen, K.L.; De Chiara, F.; Rombouts, K.; Vilstrup, H.; Andreola, F.; Mookerjee, R.P.; Jalan, R. Ammonia: A novel target for the treatment of non-alcoholic steatohepatitis. Med. Hypotheses 2018, 113, 91-97. [CrossRef]

119. Richardson, A.J.; McKain, N.; Wallace, R.J. Ammonia production by human faecal bacteria, and the enumeration, isolation and characterization of bacteria capable of growth on peptides and amino acids. BMC Microbiol. 2013, 13, 6. [CrossRef]

120. Lykke Eriksen, P.; Sørensen, M.; Grønbæk, H.; Hamilton-Dutoit, S.; Vilstrup, H.; Thomsen, K.L. Non-alcoholic fatty liver disease causes dissociated changes in metabolic liver functions. Clin. Res. Hepatol. Gastroenterol. 2019, 43, 551-560. [CrossRef]

121. Begriche, K.; Massart, J.; Robin, M.A.; Bonnet, F.; Fromenty, B. Mitochondrial adaptations and dysfunctions in nonalcoholic fatty liver disease. Hepatology 2013, 58, 1497-1507. [CrossRef]

122. Lebeaupin, C.; Vallée, D.; Hazari, Y.; Hetz, C.; Chevet, E.; Bailly-Maitre, B. Endoplasmic reticulum stress signalling and the pathogenesis of non-alcoholic fatty liver disease. J. Hepatol. 2018, 69, 927-947. [CrossRef]

123. Bak-Fredslund, K.P.; Lykke Eriksen, P.; Munk, O.L.; Villadsen, G.E.; Keiding, S.; Sørensen, M. Metabolic liver function in humans measured by 2-(18)F-fluoro-2-deoxy-D-galactose PET/CT-reproducibility and clinical potential. EJNMMI Res. $2017,7,71$. [CrossRef] 
124. Vilstrup, H. Synthesis of urea after stimulation with amino acids: Relation to liver function. Gut 1980, 21, 990-995. [CrossRef]

125. Anthony, P.P.; Ishak, K.G.; Nayak, N.C.; Poulsen, H.E.; Scheuer, P.J.; Sobin, L.H. The morphology of cirrhosis. Recommendations on definition, nomenclature, and classification by a working group sponsored by the World Health Organization. J. Clin. Pathol. 1978, 31, 395-414. [CrossRef]

126. Thomsen, K.L.; Grønbæk, H.; Glavind, E.; Hebbard, L.; Jessen, N.; Clouston, A.; George, J.; Vilstrup, H. Experimental nonalcoholic steatohepatitis compromises ureagenesis, an essential hepatic metabolic function. Am. J. Physiol. Gastrointest. Liver Physiol. 2014, 307, G295-G301. [CrossRef]

127. Eriksen, P.L.; Vilstrup, H.; Rigbolt, K.; Suppli, M.P.; Sørensen, M.; Heebøll, S.; Veidal, S.S.; Knop, F.K.; Thomsen, K.L. Non-alcoholic fatty liver disease alters expression of genes governing hepatic nitrogen conversion. Liver Int. 2019, 39, 2094-2101. [CrossRef]

128. Pessayre, D.; Fromenty, B. NASH: A mitochondrial disease. J. Hepatol. 2005, 42, 928-940. [CrossRef]

129. Marini, J.C.; Broussard, S.R. Hyperammonemia increases sensitivity to LPS. Mol. Genet. Metab. 2006, 88, 131-137. [CrossRef]

130. Jover, R.; Rodrigo, R.; Felipo, V.; Insausti, R.; Sáez-Valero, J.; García-Ayllón, M.S.; Suárez, I.; Candela, A.; Compañ, A.; Esteban, A.; et al. Brain edema and inflammatory activation in bile duct ligated rats with diet-induced hyperammonemia: A model of hepatic encephalopathy in cirrhosis. Hepatology 2006, 43, 1257-1266. [CrossRef]

131. Wright, G.; Davies, N.A.; Shawcross, D.L.; Hodges, S.J.; Zwingmann, C.; Brooks, H.F.; Mani, A.R.; Harry, D.; Stadlbauer, V.; Zou, Z.; et al. Endotoxemia produces coma and brain swelling in bile duct ligated rats. Hepatology 2007, 45, 1517-1526. [CrossRef]

132. Wright, G.; Jalan, R. Ammonia and inflammation in the pathogenesis of hepatic encephalopathy: Pandora's box? Hepatology 2007, 46, 291-294. [CrossRef]

133. Häussinger, D.; Kircheis, G.; Fischer, R.; Schliess, F.; vom Dahl, S. Hepatic encephalopathy in chronic liver disease: A clinical manifestation of astrocyte swelling and low-grade cerebral edema? J. Hepatol. 2000, 32, 1035-1038. [CrossRef]

134. Kimelberg, H.K. Astrocytic swelling in cerebral ischemia as a possible cause of injury and target for therapy. Glia 2005, 50, 389-397. [CrossRef]

135. Rodrigo, R.; Cauli, O.; Gomez-Pinedo, U.; Agusti, A.; Hernandez-Rabaza, V.; Garcia-Verdugo, J.M.; Felipo, V. Hyperammonemia induces neuroinflammation that contributes to cognitive impairment in rats with hepatic encephalopathy. Gastroenterology 2010, 139, 675-684. [CrossRef] [PubMed]

136. Zemtsova, I.; Görg, B.; Keitel, V.; Bidmon, H.J.; Schrör, K.; Häussinger, D. Microglia activation in hepatic encephalopathy in rats and humans. Hepatology 2011, 54, 204-215. [CrossRef] [PubMed]

137. Cagnin, A.; Taylor-Robinson, S.D.; Forton, D.M.; Banati, R.B. In vivo imaging of cerebral "peripheral benzodiazepine binding sites" in patients with hepatic encephalopathy. Gut 2006, 55, 547-553. [CrossRef]

138. Balzano, T.; Dadsetan, S.; Forteza, J.; Cabrera-Pastor, A.; Taoro-Gonzalez, L.; Malaguarnera, M.; Gil-Perotin, S.; Cubas-Nuñez, L.; Casanova, B.; Castro-Quintas, A.; et al. Chronic hyperammonemia induces peripheral inflammation that leads to cognitive impairment in rats: Reversed by anti-TNF- $\alpha$ treatment. J. Hepatol. 2020, 73, 582-592. [CrossRef]

139. Higarza, S.G.; Arboleya, S.; Gueimonde, M.; Gómez-Lázaro, E.; Arias, J.L.; Arias, N. Neurobehavioral dysfunction in non-alcoholic steatohepatitis is associated with hyperammonemia, gut dysbiosis, and metabolic and functional brain regional deficits. PLoS ONE 2019, 14, e0223019. [CrossRef] [PubMed]

140. Ahluwalia, V.; Betrapally, N.S.; Hylemon, P.B.; White, M.B.; Gillevet, P.M.; Unser, A.B.; Fagan, A.; Daita, K.; Heuman, D.M.; Zhou, H.; et al. Impaired Gut-Liver-Brain Axis in Patients with Cirrhosis. Sci. Rep. 2016, 6, 26800. [CrossRef]

141. Bajaj, J.S.; Kassam, Z.; Fagan, A.; Gavis, E.A.; Liu, E.; Cox, I.J.; Kheradman, R.; Heuman, D.; Wang, J.; Gurry, T.; et al. Fecal microbiota transplant from a rational stool donor improves hepatic encephalopathy: A randomized clinical trial. Hepatology 2017, 66, 1727-1738. [CrossRef]

142. Vilstrup, H.; Amodio, P.; Bajaj, J.; Cordoba, J.; Ferenci, P.; Mullen, K.D.; Weissenborn, K.; Wong, P. Hepatic encephalopathy in chronic liver disease: 2014 Practice Guideline by the American Association for the Study of Liver Diseases and the European Association for the Study of the Liver. Hepatology 2014, 60, 715-735. [CrossRef]

143. Qin, N.; Yang, F.; Li, A.; Prifti, E.; Chen, Y.; Shao, L.; Guo, J.; Le Chatelier, E.; Yao, J.; Wu, L.; et al. Alterations of the human gut microbiome in liver cirrhosis. Nature 2014, 513, 59-64. [CrossRef] [PubMed]

144. Bauer, T.M.; Schwacha, H.; Steinbrückner, B.; Brinkmann, F.E.; Ditzen, A.K.; Aponte, J.J.; Pelz, K.; Berger, D.; Kist, M.; Blum, H.E. Small intestinal bacterial overgrowth in human cirrhosis is associated with systemic endotoxemia. Am. J. Gastroenterol. 2002, 97, 2364-2370. [CrossRef] [PubMed]

145. Bajaj, J.S.; Betrapally, N.S.; Hylemon, P.B.; Heuman, D.M.; Daita, K.; White, M.B.; Unser, A.; Thacker, L.R.; Sanyal, A.J.; Kang, D.J.; et al. Salivary microbiota reflects changes in gut microbiota in cirrhosis with hepatic encephalopathy. Hepatology 2015, 62, 1260-1271. [CrossRef]

146. Li, D.Y.; Yang, M.; Edwards, S.; Ye, S.Q. Nonalcoholic fatty liver disease: For better or worse, blame the gut microbiota? JPEN J. Parenter. Enteral. Nutr. 2013, 37, 787-793. [CrossRef]

147. Hamurcu Varol, P.; Kaya, E.; Alphan, E.; Yilmaz, Y. Role of intensive dietary and lifestyle interventions in the treatment of lean nonalcoholic fatty liver disease patients. Eur. J. Gastroenterol. Hepatol. 2020, 32, 1352-1357. [CrossRef] [PubMed]

148. Chalasani, N.; Younossi, Z.; Lavine, J.E.; Charlton, M.; Cusi, K.; Rinella, M.; Harrison, S.A.; Brunt, E.M.; Sanyal, A.J. The diagnosis and management of nonalcoholic fatty liver disease: Practice guidance from the American Association for the Study of Liver Diseases. Hepatology 2018, 67, 328-357. [CrossRef] 
149. Savard, C.; Tartaglione, E.V.; Kuver, R.; Haigh, W.G.; Farrell, G.C.; Subramanian, S.; Chait, A.; Yeh, M.M.; Quinn, L.S.; Ioannou, G.N. Synergistic interaction of dietary cholesterol and dietary fat in inducing experimental steatohepatitis. Hepatology 2013, 57, 81-92. [CrossRef]

150. Murphy, E.F.; Cotter, P.D.; Healy, S.; Marques, T.M.; O'Sullivan, O.; Fouhy, F.; Clarke, S.F.; O'Toole, P.W.; Quigley, E.M.; Stanton, C.; et al. Composition and energy harvesting capacity of the gut microbiota: Relationship to diet, obesity and time in mouse models. Gut 2010, 59, 1635-1642. [CrossRef]

151. Turnbaugh, P.J.; Bäckhed, F.; Fulton, L.; Gordon, J.I. Diet-induced obesity is linked to marked but reversible alterations in the mouse distal gut microbiome. Cell Host Microbe 2008, 3, 213-223. [CrossRef] [PubMed]

152. Jakobsdottir, G.; Xu, J.; Molin, G.; Ahrné, S.; Nyman, M. High-fat diet reduces the formation of butyrate, but increases succinate, inflammation, liver fat and cholesterol in rats, while dietary fibre counteracts these effects. PLoS ONE 2013, 8, e80476. [CrossRef]

153. Stanhope, K.L.; Schwarz, J.M.; Keim, N.L.; Griffen, S.C.; Bremer, A.A.; Graham, J.L.; Hatcher, B.; Cox, C.L.; Dyachenko, A.; Zhang, W.; et al. Consuming fructose-sweetened, not glucose-sweetened, beverages increases visceral adiposity and lipids and decreases insulin sensitivity in overweight/obese humans. J. Clin. Investig. 2009, 119, 1322-1334. [CrossRef] [PubMed]

154. Basaranoglu, M.; Basaranoglu, G.; Sabuncu, T.; Sentürk, H. Fructose as a key player in the development of fatty liver disease. World J. Gastroenterol. 2013, 19, 1166-1172. [CrossRef]

155. Rojas, A.; González, I.; Rodríguez, B.; Romero, J.; Figueroa, H.; Llanos, J.; Morales, E.; Pérez-Castro, R. Evidence of involvement of the receptor for advanced glycation end-products (RAGE) in the adhesion of Helicobacter pylori to gastric epithelial cells. Microbes Infect. 2011, 13, 818-823. [CrossRef]

156. Ciccocioppo, R.; Vanoli, A.; Klersy, C.; Imbesi, V.; Boccaccio, V.; Manca, R.; Betti, E.; Cangemi, G.C.; Strada, E.; Besio, R.; et al. Role of the advanced glycation end products receptor in Crohn's disease inflammation. World J. Gastroenterol. 2013, 19, 8269-8281. [CrossRef]

157. Leung, C.; Herath, C.B.; Jia, Z.; Andrikopoulos, S.; Brown, B.E.; Davies, M.J.; Rivera, L.R.; Furness, J.B.; Forbes, J.M.; Angus, P.W. Dietary advanced glycation end-products aggravate non-alcoholic fatty liver disease. World J. Gastroenterol. 2016, 22, 8026-8040. [CrossRef]

158. Molloy, J.W.; Calcagno, C.J.; Williams, C.D.; Jones, F.J.; Torres, D.M.; Harrison, S.A. Association of coffee and caffeine consumption with fatty liver disease, nonalcoholic steatohepatitis, and degree of hepatic fibrosis. Hepatology 2012, 55, 429-436. [CrossRef] [PubMed]

159. Vitaglione, P.; Morisco, F.; Mazzone, G.; Amoruso, D.C.; Ribecco, M.T.; Romano, A.; Fogliano, V.; Caporaso, N.; D'Argenio, G. Coffee reduces liver damage in a rat model of steatohepatitis: The underlying mechanisms and the role of polyphenols and melanoidins. Hepatology 2010, 52, 1652-1661. [CrossRef] [PubMed]

160. Cowan, T.E.; Palmnäs, M.S.; Yang, J.; Bomhof, M.R.; Ardell, K.L.; Reimer, R.A.; Vogel, H.J.; Shearer, J. Chronic coffee consumption in the diet-induced obese rat: Impact on gut microbiota and serum metabolomics. J. Nutr. Biochem. 2014, 25, 489-495. [CrossRef] [PubMed]

161. Nakayama, T.; Oishi, K. Influence of coffee (Coffea arabica) and galacto-oligosaccharide consumption on intestinal microbiota and the host responses. FEMS Microbiol. Lett. 2013, 343, 161-168. [CrossRef]

162. Kennedy, O.J.; Roderick, P.; Buchanan, R.; Fallowfield, J.A.; Hayes, P.C.; Parkes, J. Systematic review with meta-analysis: Coffee consumption and the risk of cirrhosis. Aliment. Pharmacol. Ther. 2016, 43, 562-574. [CrossRef] [PubMed]

163. Setiawan, V.W.; Wilkens, L.R.; Lu, S.C.; Hernandez, B.Y.; Le Marchand, L.; Henderson, B.E. Association of coffee intake with reduced incidence of liver cancer and death from chronic liver disease in the US multiethnic cohort. Gastroenterology 2015, 148, 118-125.e15. [CrossRef]

164. Hodge, A.; Lim, S.; Goh, E.; Wong, O.; Marsh, P.; Knight, V.; Sievert, W.; de Courten, B. Coffee Intake Is Associated with a Lower Liver Stiffness in Patients with Non-Alcoholic Fatty Liver Disease, Hepatitis C, and Hepatitis B. Nutrients 2017, 9, 56. [CrossRef] [PubMed]

165. Seo, D.B.; Jeong, H.W.; Cho, D.; Lee, B.J.; Lee, J.H.; Choi, J.Y.; Bae, I.H.; Lee, S.J. Fermented green tea extract alleviates obesity and related complications and alters gut microbiota composition in diet-induced obese mice. J. Med. Food 2015, 18, 549-556. [CrossRef] [PubMed]

166. Zhou, J.; Farah, B.L.; Sinha, R.A.; Wu, Y.; Singh, B.K.; Bay, B.H.; Yang, C.S.; Yen, P.M. Epigallocatechin-3-gallate (EGCG), a green tea polyphenol, stimulates hepatic autophagy and lipid clearance. PLoS ONE 2014, 9, e87161. [CrossRef]

167. Santamarina, A.B.; Carvalho-Silva, M.; Gomes, L.M.; Okuda, M.H.; Santana, A.A.; Streck, E.L.; Seelaender, M.; do Nascimento, C.M.; Ribeiro, E.B.; Lira, F.S.; et al. Decaffeinated green tea extract rich in epigallocatechin-3-gallate prevents fatty liver disease by increased activities of mitochondrial respiratory chain complexes in diet-induced obesity mice. J. Nutr. Biochem. 2015, 26, 1348-1356. [CrossRef]

168. Pezeshki, A.; Safi, S.; Feizi, A.; Askari, G.; Karami, F. The Effect of Green Tea Extract Supplementation on Liver Enzymes in Patients with Nonalcoholic Fatty Liver Disease. Int. J. Prev. Med. 2016, 7, 28. [CrossRef]

169. Sakata, R.; Nakamura, T.; Torimura, T.; Ueno, T.; Sata, M. Green tea with high-density catechins improves liver function and fat infiltration in non-alcoholic fatty liver disease (NAFLD) patients: A double-blind placebo-controlled study. Int. J. Mol. Med. 2013, 32, 989-994. [CrossRef]

170. Lu, W.; Li, S.; Li, J.; Wang, J.; Zhang, R.; Zhou, Y.; Yin, Q.; Zheng, Y.; Wang, F.; Xia, Y.; et al. Effects of Omega-3 Fatty Acid in Nonalcoholic Fatty Liver Disease: A Meta-Analysis. Gastroenterol. Res. Pract. 2016, 2016, 1459790. [CrossRef] 
171. Di Minno, M.N.; Russolillo, A.; Lupoli, R.; Ambrosino, P.; Di Minno, A.; Tarantino, G. Omega-3 fatty acids for the treatment of non-alcoholic fatty liver disease. World J. Gastroenterol. 2012, 18, 5839-5847. [CrossRef]

172. Bashiardes, S.; Shapiro, H.; Rozin, S.; Shibolet, O.; Elinav, E. Non-alcoholic fatty liver and the gut microbiota. Mol. Metab. 2016, 5, 782-794. [CrossRef] [PubMed]

173. Carbajo-Pescador, S.; Porras, D.; García-Mediavilla, M.V.; Martínez-Flórez, S.; Juarez-Fernández, M.; Cuevas, M.J.; Mauriz, J.L.; González-Gallego, J.; Nistal, E.; Sánchez-Campos, S. Beneficial effects of exercise on gut microbiota functionality and barrier integrity, and gut-liver crosstalk in an in vivo model of early obesity and non-alcoholic fatty liver disease. Dis. Models Mech. 2019, 12, dmm039206. [CrossRef]

174. Baker, C.J.; Martinez-Huenchullan, S.F.; D'Souza, M.; Xu, Y.; Li, M.; Bi, Y.; Johnson, N.A.; Twigg, S.M. Effect of exercise on hepatic steatosis: Are benefits seen without dietary intervention? A systematic review and meta-analysis. J. Diabetes 2021, $13,63-77$. [CrossRef]

175. Huber, Y.; Pfirrmann, D.; Gebhardt, I.; Labenz, C.; Gehrke, N.; Straub, B.K.; Ruckes, C.; Bantel, H.; Belda, E.; Clément, K.; et al. Improvement of non-invasive markers of NAFLD from an individualised, web-based exercise program. Aliment. Pharmacol. Ther. 2019, 50, 930-939. [CrossRef] [PubMed]

176. Høier, B.; Rufener, N.; Bojsen-Møller, J.; Bangsbo, J.; Hellsten, Y. The effect of passive movement training on angiogenic factors and capillary growth in human skeletal muscle. J. Physiol. 2010, 588, 3833-3845. [CrossRef] [PubMed]

177. Arulanandan, A.; Ang, B.; Bettencourt, R.; Hooker, J.; Behling, C.; Lin, G.Y.; Valasek, M.A.; Ix, J.H.; Schnabl, B.; Sirlin, C.B.; et al. Association Between Quantity of Liver Fat and Cardiovascular Risk in Patients With Nonalcoholic Fatty Liver Disease Independent of Nonalcoholic Steatohepatitis. Clin. Gastroenterol. Hepatol. 2015, 13, 1513-1520.e1511. [CrossRef] [PubMed]

178. Hashida, R.; Kawaguchi, T.; Bekki, M.; Omoto, M.; Matsuse, H.; Nago, T.; Takano, Y.; Ueno, T.; Koga, H.; George, J.; et al. Aerobic vs. resistance exercise in non-alcoholic fatty liver disease: A systematic review. J. Hepatol. 2017, 66, 142-152. [CrossRef] [PubMed]

179. Ortiz-Alvarez, L.; Xu, H.; Martinez-Tellez, B. Influence of Exercise on the Human Gut Microbiota of Healthy Adults: A Systematic Review. Clin. Transl. Gastroenterol. 2020, 11, e00126. [CrossRef]

180. Monda, V.; Villano, I.; Messina, A.; Valenzano, A.; Esposito, T.; Moscatelli, F.; Viggiano, A.; Cibelli, G.; Chieffi, S.; Monda, M.; et al. Exercise Modifies the Gut Microbiota with Positive Health Effects. Oxid. Med. Cell. Longev. 2017, 2017, 3831972. [CrossRef]

181. Mailing, L.J.; Allen, J.M.; Buford, T.W.; Fields, C.J.; Woods, J.A. Exercise and the Gut Microbiome: A Review of the Evidence, Potential Mechanisms, and Implications for Human Health. Exerc. Sport Sci. Rev. 2019, 47, 75-85. [CrossRef] [PubMed]

182. Welly, R.J.; Liu, T.W.; Zidon, T.M.; Rowles, J.L., 3rd; Park, Y.M.; Smith, T.N.; Swanson, K.S.; Padilla, J.; Vieira-Potter, V.J. Comparison of Diet versus Exercise on Metabolic Function and Gut Microbiota in Obese Rats. Med. Sci. Sports Exerc. 2016, 48, 1688-1698. [CrossRef] [PubMed]

183. Barton, W.; Penney, N.C.; Cronin, O.; Garcia-Perez, I.; Molloy, M.G.; Holmes, E.; Shanahan, F.; Cotter, P.D.; O'Sullivan, O. The microbiome of professional athletes differs from that of more sedentary subjects in composition and particularly at the functional metabolic level. Gut 2018, 67, 625-633. [CrossRef] [PubMed]

184. Allen, J.M.; Mailing, L.J.; Niemiro, G.M.; Moore, R.; Cook, M.D.; White, B.A.; Holscher, H.D.; Woods, J.A. Exercise Alters Gut Microbiota Composition and Function in Lean and Obese Humans. Med. Sci. Sports Exerc. 2018, 50, 747-757. [CrossRef]

185. Vallianou, N.; Dalamaga, M.; Stratigou, T.; Karampela, I.; Tsigalou, C. Do Antibiotics Cause Obesity Through Long-term Alterations in the Gut Microbiome? A Review of Current Evidence. Curr. Obes. Rep. 2021, 10, 244-262. [CrossRef]

186. Munukka, E.; Ahtiainen, J.P.; Puigbó, P.; Jalkanen, S.; Pahkala, K.; Keskitalo, A.; Kujala, U.M.; Pietilä, S.; Hollmén, M.; Elo, L.; et al. Six-Week Endurance Exercise Alters Gut Metagenome That Is not Reflected in Systemic Metabolism in Over-weight Women. Front. Microbiol. 2018, 9, 2323. [CrossRef]

187. Sjöström, L.; Narbro, K.; Sjöström, C.D.; Karason, K.; Larsson, B.; Wedel, H.; Lystig, T.; Sullivan, M.; Bouchard, C.; Carlsson, B.; et al. Effects of bariatric surgery on mortality in Swedish obese subjects. N. Engl. J. Med. 2007, 357, 741-752. [CrossRef]

188. Adams, T.D.; Davidson, L.E.; Litwin, S.E.; Kim, J.; Kolotkin, R.L.; Nanjee, M.N.; Gutierrez, J.M.; Frogley, S.J.; Ibele, A.R.; Brinton, E.A.; et al. Weight and Metabolic Outcomes 12 Years after Gastric Bypass. N. Engl. J. Med. 2017, 377, 1143-1155. [CrossRef]

189. Steenackers, N.; Vanuytsel, T.; Augustijns, P.; Tack, J.; Mertens, A.; Lannoo, M.; Van der Schueren, B.; Matthys, C. Adaptations in gastrointestinal physiology after sleeve gastrectomy and Roux-en-Y gastric bypass. Lancet Gastroenterol. Hepatol. 2021, 6, $225-237$. [CrossRef]

190. Karami, R.; Kermansaravi, M.; Pishgahroudsari, M.; Talebi, M.; Mohammadzadeh, N.; Pazouki, A. Changes in gut microbial flora after Roux-en-Y gastric bypass and sleeve gastrectomy and their effects on post-operative weight loss. Updates Surg. 2021, 73, 1493-1499. [CrossRef]

191. Steinert, R.E.; Rehman, A.; Souto Lima, E.J.; Agamennone, V.; Schuren, F.H.J.; Gero, D.; Schreiner, P.; Vonlanthen, R.; Ismaeil, A.; Tzafos, S.; et al. Roux-en-Y gastric bypass surgery changes fungal and bacterial microbiota in morbidly obese patients-A pilot study. PLOS ONE 2020, 15, e0236936. [CrossRef]

192. Farin, W.; Oñate, F.P.; Plassais, J.; Bonny, C.; Beglinger, C.; Woelnerhanssen, B.; Nocca, D.; Magoules, F.; Le Chatelier, E.; Pons, N.; et al. Impact of laparoscopic Roux-en-Y gastric bypass and sleeve gastrectomy on gut microbiota: A metagenomic comparative analysis. Surg. Obes. Relat. Dis. 2020, 16, 852-862. [CrossRef] [PubMed]

193. Palleja, A.; Kashani, A.; Allin, K.H.; Nielsen, T.; Zhang, C.; Li, Y.; Brach, T.; Liang, S.; Feng, Q.; Jørgensen, N.B.; et al. Roux-en-Y gastric bypass surgery of morbidly obese patients induces swift and persistent changes of the individual gut microbiota. Genome Med. 2016, 8, 67. [CrossRef] [PubMed] 
194. Lopez-Siles, M.; Duncan, S.H.; Garcia-Gil, L.J.; Martinez-Medina, M. Faecalibacterium prausnitzii: From microbiology to diagnostics and prognostics. ISME J. 2017, 11, 841-852. [CrossRef]

195. Lenoir, M.; Martín, R.; Torres-Maravilla, E.; Chadi, S.; González-Dávila, P.; Sokol, H.; Langella, P.; Chain, F.; Bermúdez-Humarán, L.G. Butyrate mediates anti-inflammatory effects of Faecalibacterium prausnitzii in intestinal epithelial cells through Dact3. Gut Microbes 2020, 12, 1-16. [CrossRef]

196. Zhang, M.; Zhou, L.; Wang, Y.; Dorfman, R.G.; Tang, D.; Xu, L.; Pan, Y.; Zhou, Q.; Li, Y.; Yin, Y.; et al. Faecalibacterium prausnitzii produces butyrate to decrease c-Myc-related metabolism and Th17 differentiation by inhibiting histone deacetylase 3 . Int. Immunol. 2019, 31, 499-514. [CrossRef]

197. Tabasi, M.; Eybpoosh, S.; Siadat, S.D.; Elyasinia, F.; Soroush, A.; Bouzari, S. Modulation of the Gut Microbiota and Serum Biomarkers After Laparoscopic Sleeve Gastrectomy: A 1-Year Follow-Up Study. Obes. Surg. 2021, 31, 1949-1956. [CrossRef]

198. Tremaroli, V.; Karlsson, F.; Werling, M.; Ståhlman, M.; Kovatcheva-Datchary, P.; Olbers, T.; Fändriks, L.; le Roux, C.W.; Nielsen, J.; Bäckhed, F. Roux-en-Y Gastric Bypass and Vertical Banded Gastroplasty Induce Long-Term Changes on the Human Gut Microbiome Contributing to Fat Mass Regulation. Cell Metab. 2015, 22, 228-238. [CrossRef]

199. Faria, S.L.; Santos, A.; Magro, D.O.; Cazzo, E.; Assalin, H.B.; Guadagnini, D.; Vieira, F.T.; Dutra, E.S.; Saad, M.J.A.; Ito, M.K. Gut Microbiota Modifications and Weight Regain in Morbidly Obese Women After Roux-en-Y Gastric Bypass. Obes. Surg. 2020, 30, 4958-4966. [CrossRef]

200. Hill, C.; Guarner, F.; Reid, G.; Gibson, G.R.; Merenstein, D.J.; Pot, B.; Morelli, L.; Canani, R.B.; Flint, H.J.; Salminen, S.; et al. Expert consensus document. The International Scientific Association for Probiotics and Prebiotics consensus statement on the scope and appropriate use of the term probiotic. Nat. Rev. Gastroenterol. Hepatol. 2014, 11, 506-514. [CrossRef]

201. Hoffmann, D.E.; Fraser, C.M.; Palumbo, F.; Ravel, J.; Rowthorn, V.; Schwartz, J. Probiotics: Achieving a better regulatory fit. Food Drug Law J. 2014, 69, 237-272.

202. Paolella, G.; Mandato, C.; Pierri, L.; Poeta, M.; Di Stasi, M.; Vajro, P. Gut-liver axis and probiotics: Their role in non-alcoholic fatty liver disease. World J. Gastroenterol. 2014, 20, 15518-15531. [CrossRef]

203. Govender, M.; Choonara, Y.E.; Kumar, P.; du Toit, L.C.; van Vuuren, S.; Pillay, V. A review of the advancements in probiotic delivery: Conventional vs. non-conventional formulations for intestinal flora supplementation. AAPS PharmSciTech. 2014, 15, 29-43. [CrossRef] [PubMed]

204. Alisi, A.; Bedogni, G.; Baviera, G.; Giorgio, V.; Porro, E.; Paris, C.; Giammaria, P.; Reali, L.; Anania, F.; Nobili, V. Randomised clinical trial: The beneficial effects of VSL\#3 in obese children with non-alcoholic steatohepatitis. Aliment. Pharmacol. Ther. 2014, 39, 1276-1285. [CrossRef] [PubMed]

205. Loguercio, C.; Federico, A.; Tuccillo, C.; Terracciano, F.; D’Auria, M.V.; De Simone, C.; Del Vecchio Blanco, C. Beneficial effects of a probiotic VSL\#3 on parameters of liver dysfunction in chronic liver diseases. J. Clin. Gastroenterol. 2005, 39, 540-543. [CrossRef]

206. Sokol, H.; Pigneur, B.; Watterlot, L.; Lakhdari, O.; Bermúdez-Humarán, L.G.; Gratadoux, J.J.; Blugeon, S.; Bridonneau, C.; Furet, J.P.; Corthier, G.; et al. Faecalibacterium prausnitzii is an anti-inflammatory commensal bacterium identified by gut microbiota analysis of Crohn disease patients. Proc. Natl. Acad. Sci. USA 2008, 105, 16731-16736. [CrossRef] [PubMed]

207. Munukka, E.; Rintala, A.; Toivonen, R.; Nylund, M.; Yang, B.; Takanen, A.; Hänninen, A.; Vuopio, J.; Huovinen, P.; Jalkanen, S.; et al. Faecalibacterium prausnitzii treatment improves hepatic health and reduces adipose tissue inflammation in high-fat fed mice. ISME J. 2017, 11, 1667-1679. [CrossRef]

208. Gómez-Gallego, C.; Pohl, S.; Salminen, S.; De Vos, W.M.; Kneifel, W. Akkermansia muciniphila: A novel functional microbe with probiotic properties. Benef. Microbes 2016, 7, 571-584. [CrossRef]

209. Stenman, L.K.; Burcelin, R.; Lahtinen, S. Establishing a causal link between gut microbes, body weight gain and glucose metabolism in humans-Towards treatment with probiotics. Benef. Microbes 2016, 7, 11-22. [CrossRef]

210. Plovier, H.; Everard, A.; Druart, C.; Depommier, C.; Van Hul, M.; Geurts, L.; Chilloux, J.; Ottman, N.; Duparc, T.; Lichtenstein, L.; et al. A purified membrane protein from Akkermansia muciniphila or the pasteurized bacterium improves metabolism in obese and diabetic mice. Nat. Med. 2017, 23, 107-113. [CrossRef]

211. Zhao, S.; Liu, W.; Wang, J.; Shi, J.; Sun, Y.; Wang, W.; Ning, G.; Liu, R.; Hong, J. Akkermansia muciniphila improves metabolic profiles by reducing inflammation in chow diet-fed mice. J. Mol. Endocrinol. 2017, 58, 1-14. [CrossRef]

212. Gao, X.; Zhu, Y.; Wen, Y.; Liu, G.; Wan, C. Efficacy of probiotics in non-alcoholic fatty liver disease in adult and children: A meta-analysis of randomized controlled trials. Hepatol. Res. 2016, 46, 1226-1233. [CrossRef] [PubMed]

213. Ma, Y.Y.; Li, L.; Yu, C.H.; Shen, Z.; Chen, L.H.; Li, Y.M. Effects of probiotics on nonalcoholic fatty liver disease: A meta-analysis. World J. Gastroenterol. 2013, 19, 6911-6918. [CrossRef]

214. Shavakhi, A.; Minakari, M.; Firouzian, H.; Assali, R.; Hekmatdoost, A.; Ferns, G. Effect of a Probiotic and Metformin on Liver Aminotransferases in Non-alcoholic Steatohepatitis: A Double Blind Randomized Clinical Trial. Int. J. Prev. Med. 2013, 4, 531-537.

215. Vallianou, N.; Stratigou, T.; Christodoulatos, G.S.; Tsigalou, C.; Dalamaga, M. Probiotics, Prebiotics, Synbiotics, Postbiotics, and Obesity: Current Evidence, Controversies, and Perspectives. Curr. Obes. Rep. 2020, 9, 179-192. [CrossRef]

216. Reijnders, D.; Goossens, G.H.; Hermes, G.D.; Neis, E.P.; van der Beek, C.M.; Most, J.; Holst, J.J.; Lenaerts, K.; Kootte, R.S.; Nieuwdorp, M.; et al. Effects of Gut Microbiota Manipulation by Antibiotics on Host Metabolism in Obese Humans: A Randomized Double-Blind Placebo-Controlled Trial. Cell Metab. 2016, 24, 63-74. [CrossRef] [PubMed] 
217. Gangarapu, V.; Ince, A.T.; Baysal, B.; Kayar, Y.; Kılıç, U.; Gök, Ö.; Uysal, Ö.; Şenturk, H. Efficacy of rifaximin on circulating endotoxins and cytokines in patients with nonalcoholic fatty liver disease. Eur. J. Gastroenterol. Hepatol. 2015, $27,840-845$. [CrossRef] [PubMed]

218. van Nood, E.; Vrieze, A.; Nieuwdorp, M.; Fuentes, S.; Zoetendal, E.G.; de Vos, W.M.; Visser, C.E.; Kuijper, E.J.; Bartelsman, J.F.; Tijssen, J.G.; et al. Duodenal infusion of donor feces for recurrent Clostridium difficile. N. Engl. J. Med. 2013, 368, 407-415. [CrossRef]

219. Kelly, C.R.; Kim, A.M.; Laine, L.; Wu, G.D. The AGA's Fecal Microbiota Transplantation National Registry: An Important Step Toward Understanding Risks and Benefits of Microbiota Therapeutics. Gastroenterology 2017, 152, 681-684. [CrossRef]

220. Vrieze, A.; Van Nood, E.; Holleman, F.; Salojärvi, J.; Kootte, R.S.; Bartelsman, J.F.; Dallinga-Thie, G.M.; Ackermans, M.T.; Serlie, M.J.; Oozeer, R.; et al. Transfer of intestinal microbiota from lean donors increases insulin sensitivity in individuals with metabolic syndrome. Gastroenterology 2012, 143, 913-916.e917. [CrossRef] [PubMed]

221. Zhou, D.; Pan, Q.; Shen, F.; Cao, H.X.; Ding, W.J.; Chen, Y.W.; Fan, J.G. Total fecal microbiota transplantation alleviates high-fat diet-induced steatohepatitis in mice via beneficial regulation of gut microbiota. Sci. Rep. 2017, 7, 1529. [CrossRef]

222. Li, S.S.; Zhu, A.; Benes, V.; Costea, P.I.; Hercog, R.; Hildebrand, F.; Huerta-Cepas, J.; Nieuwdorp, M.; Salojärvi, J.; Voigt, A.Y.; et al. Durable coexistence of donor and recipient strains after fecal microbiota transplantation. Science 2016, 352, 586-589. [CrossRef] [PubMed]

223. Bajaj, J.S.; Salzman, N.H.; Acharya, C.; Sterling, R.K.; White, M.B.; Gavis, E.A.; Fagan, A.; Hayward, M.; Holtz, M.L.; Matherly, S.; et al. Fecal Microbial Transplant Capsules Are Safe in Hepatic Encephalopathy: A Phase 1, Randomized, Placebo-Controlled Trial. Hepatology 2019, 70, 1690-1703. [CrossRef]

224. Philips, C.A.; Pande, A.; Shasthry, S.M.; Jamwal, K.D.; Khillan, V.; Chandel, S.S.; Kumar, G.; Sharma, M.K.; Maiwall, R.; Jindal, A.; et al. Healthy Donor Fecal Microbiota Transplantation in Steroid-Ineligible Severe Alcoholic Hepatitis: A Pilot Study. Clin. Gastroenterol. Hepatol. 2017, 15, 600-602. [CrossRef]

225. Duan, Y.; Llorente, C.; Lang, S.; Brandl, K.; Chu, H.; Jiang, L.; White, R.C.; Clarke, T.H.; Nguyen, K.; Torralba, M.; et al. Bacteriophage targeting of gut bacterium attenuates alcoholic liver disease. Nature 2019, 575, 505-511. [CrossRef] [PubMed]

226. Górski, A.; Bollyky, P.L.; Przybylski, M.; Borysowski, J.; Międzybrodzki, R.; Jończyk-Matysiak, E.; Weber-Dąbrowska, B. Perspectives of Phage Therapy in Non-bacterial Infections. Front. Microbiol. 2018, 9, 3306. [CrossRef]

227. Ramachandran, G.; Bikard, D. Editing the microbiome the CRISPR way. Philos. Trans. R. Soc. B Biol. Sci. 2019, $374,20180103$. [CrossRef] [PubMed]

228. Spyrou, N.; Vallianou, N.; Kadillari, J.; Dalamaga, M. The interplay of obesity, gut microbiome and diet in the immune check point inhibitors therapy era. Semin. Cancer Biol. 2021, 73, 356-376. [CrossRef] [PubMed] 